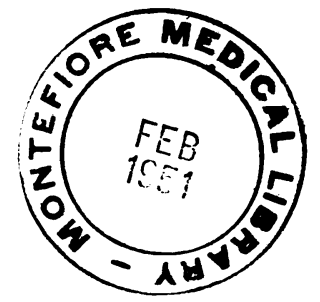

\title{
INFANTILE HEMIPLEGIA TREATED BY REMOVING ONE CEREBRAL HEMISPHERE
}

\author{
BY \\ ROWLAND A. KRYNAUW \\ From the Department of Neurosurgery, Johannesburg Hospital, South Africa
}

This preliminary communication is concerned with what I believe to be a new approach to the problem of the infantile hemiplegias. It is as well however to point out at the outset that the term infantile hemiplegia is employed here in a wide sense, and that some of the cases would, in a strict attempt at classification, fall clearly into the Little's group.

The work on which the present report is based has been carried out over a period of five years, during which time 12 hemispherectomies were performed on patients suffering from infantile hemiplegia. In no case was the hemiplegic manifestation considered as a prime indication for surgery. Convulsive and mental changes were regarded as the indications for operation, and, as will be seen from a study of the case records, I have come to consider mental deviations in the absence of epileptic phenomena, and also epileptic manifestations in the absence of definite mental or behaviour disturbances, as adequate indications for surgery. In this series there was one death, Case 6 (J.S.). The age at the time of operation in the remaining 11 cases ranged from 8 months in Case 12 (M.B.) to 21 years in Case 5 (Miss A.).

This choice of widely separated age groups has been deliberate, as we wished to gain as much knowledge as possible of the physiological, neurological, and psychological adjustments at various ages after removal of so large a part of the brain.

\section{Clinical Considerations}

Infantile hemiplegia is a common condition, and although the clinical features are well known, it might be as well to present a resumé of the symptom complex.

Hemiplegia.-The hemiplegic element usually affects the arm, leg, and face, with the arm always affected to a greater degree than the leg and face. The weakness is usually of a spastic type, and in most cases the arm assumes a typical posture of adduction at the shoulder and flexion at the elbow and wrist. In some instances extensor movements are almost impossible. In the lower limb the greatest weakness is seen in the dorsiflexors and evertors of the foot. Contractures tend to fix the limbs in paralytic attitudes. However incapable the upper limb may be, most of these patients eventually learn to walk, with a greater or lesser degree of weakness, spasticity, and deformity. Many cases have little contracture, but exhibit an ataxic or athetoid awkwardness of the affected limbs, resulting in what Wilson described as a "gaucherie of volitional act". Underdevelopment of the affected limbs, both in length and bulk, is a constant finding. Trophic and vasomotor changes have been described, but these have been minimal in our experience. The face is little, if at all, affected, but a radiograph of the skull invariably demonstrates a considerably smaller compartment on the side of the affected hemisphere, which is the side opposite to that of the general growth impairment. Choreo-athetoid movements, sometimes with the limbs at rest, but usually the accompaniment of volitional endeavour, were a prominent feature in all our cases, but here again the upper limb seems most severely affected.

Epilepsy.-Epileptic convulsions occur in the majority of cases ; these are often focal and of the Jacksonian type, but generalized seizures, psychomotor equivalents, and petit mal, have all been observed. Osler stressed that "one of the most common and distressing symptoms is the occurrence of convulsive seizures", but he also said that, " more distressing still to the relatives is the enfeebled mental state which so often follows infantile hemiplegia".

Mental Changes.-In the cases which have come under my observation it has been the mental state which has impressed me most strongly, and in many, it has been the mental state, rather than the hemiplegia or epilepsy, which has led the parents to seek advice. The mental changes cover a wide range from virtual imbecility at the one extreme, to the mildest retardation at the other, but this is 


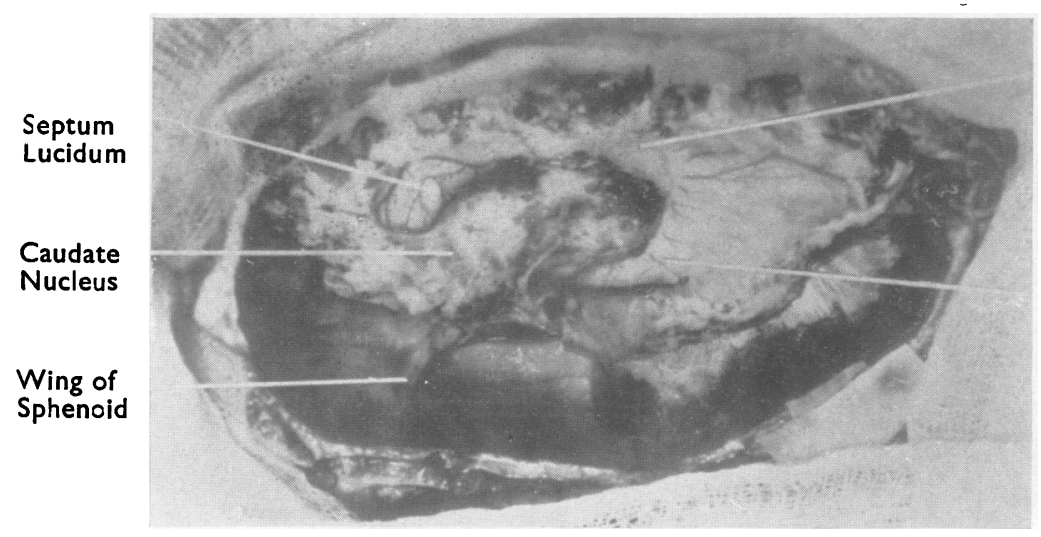

Thalamus

Tail of

Caudate

Nucleus

Fig. 1.-Basal stump after hemispherectomy. often associated with an asocial outlook, which may well be related to the convulsive episodes. In most of these patients an outstanding feature has been episodic outbursts of violent "temper tantrums" which usually have no adequate cause, are short lived, and suggest the possibility of their being epileptic equivalents. Some patients attribute their outbursts to a compulsive drive which they are unable to resist. With regard to the language function, young children who have learned to speak and then develop infantile hemiplegia may lose this function. In other cases, speech may be little disturbed.

\section{Pathological Considerations}

No neurologist would expect to find any single pathological event subserving so large and variable a grouping of symptoms and concomitant signs. The gross pathological state in our series has included porencephalic cysts, intracerebral paraventricular cysts, arachnitic watery cysts, microgyral formations, and a small sclerosed hemisphere, associated with vascular alterations in the territories of one or more of the main arteries. Each or any of these changes may be found either singly or in combination with the others. The list is not complete, but serves to indicate the wide range of pathological changes encountered. I would, however, like to stress that the findings represent pathological "end states", and are not to be regarded as progressive lesions. The pathogenesis of these established end states is not clear in all cases, but the protocols lead us to deduce that birth trauma, or later events during infancy, such as trauma, infective, embolic, or thrombotic episodes, are the chief aetiological factors.

\section{Air Studies}

The air studies play an important part in determining suitability for operation, but a less important part in determining the scope and extent of the procedure. Air pictures are presented with the individual case records, and it will be seen that apart from tne focal ventricular deformities encountered in the porencephalic group, a considerable dilatation of the ventricle on the side of the affected hemisphere has been encountered in all cases with one exception, Case 10 (P.T.). We have come too expect gross distortions in the air pictures, and provided these remain unilateral the case is regardech as suitable for hemispherectomy.

\section{Operation}

In the past the vast majority of these patient have had to rely on anticonvulsants for the manage ment of their epilepsy. Orthopaedic surgeons have directed their attention to the correction of deformities, and re-education by physical methods. Neurosurgical endeavour has been largely concerned with local and limited cerebral operations for epilepsy, where the episodes have been focal. Local excisions and incisions may in some cases stop fits, but in my experience they have no beneficial effect on the mental state, and I have noted little change in respect of physical disability. Because of this, and because of certain features of the electrocorticograms in these cases, I was led on to a more radical procedure embodying removal of the affected hemisphere, with the exception of the thalamus, the caudate nucleus and its tail. With regard to the operation, a generous lateral osteoplastic flap affords all the room that is required. The hemisphere is divided into four segments by a vertical and transverse incision of the superolateral surface extending into the ventricle. Each quadrant is dissected out, working from within the ventricle. The middle cerebral artery is taken just lateral to its antero-lateral ganglionic branches, that is, just lateral to the anterior perforated substance. The choroid plexus is carefully coagulated and removed 
from the lateral ventricle. The dura is closed carefully, and a burrhole made in the centre of the bone flap for post-operative aspirations. It will be seen that the whole of the cerebral cortex with the exception of that portion medial to the tail of the caudate nucleus is removed, together with the putamen and globus pallidus. Fig. 1 is a photograph taken at operation to show the basal stump after the hemisphere has been removed.

\section{Post-Operative Residua}

The vast implications arising from such a procedure are a source of considerable speculation, and will be dealt with more fully in a later communication. It is perhaps worth noting, however, that even when an apparently functioning motor cortex, area 4, is present, as determined by thyratron stimulation, its removal together with the lentiform complex does not result in more than a transient increase of weakness of voluntary motor power. Some movement has been present in all cases the day after operation, and in some cases a few hours afterwards. The return to pre-operative power is rapid, and is associated later with a considerable lessening of the spastic athetosis which is such a significant feature in these cases. It is further to be noted that this improvement is not just transient, and back to the pre-operative level, but is a definite progressive improvement, extending over a period of many months or years Case 1 (A.H.).

In the sensory sphere there is at first a profound loss of all cortical sensory modalities. Compensation seems to occur soon, and in all cases has been so complete within a few months that the changes no longer constitute a subjective disability. In no case has the so-called thalamic syndrome developed. Quantitative and qualitative appreciation of pain and tactile stimulation as tested by pin prick and cotton wool have returned to normal by comparison with the opposite side, and within the limits of routine tests. A contralateral homonymous hemianopia with sparing of the macula has been induced in all the cases in which this was not already present before operation, and up to the present this has remained constant. The disability is, however, one of which the patients are quite unaware, except while being specifically tested for it, a finding in accordance with other experience. In Cases 3, 8, and 12 , the remarks concerning residual phenomena only apply within the limits of our ability to examine such young patients. Other factors relating to behaviour, mentality, the intellectual sphere, voluntary and involuntary movements, spatial orientation, tactile discrimination, are all considered in individual case records.

\section{Electro-Encephalographic Changes}

EEG studies in all our cases have shown very considerable deviations from normal. In most cases it has been a non-specific dysrhythmia not confined to the affected hemisphere. In some instances a quiet area has been disclosed, which at operation later has been found to be the region overlying the porencephalic cyst. EEG records taken after removal of the affected hemisphere have shown the electrical picture rapidly settling down to within normal limits. It would appear reasonable, therefore, to suppose that the dysrhythmia encountered in the remaining hemisphere was due, in the first instance, to an overflow from the grossly abnormal high amplitude components from the opposite and pathological hemisphere via the interhemisphere communicating pathways. Herein, to my mind, is objective support for my contention that the entire hemisphere on the side of abnormal pathology should be removed. I feel that if any part of the hemisphere is retained, it will continue to inflict its unruly patterns on the opposite, anatomically normal side, with consequent disruption of its natural physiological activities, particularly those more especially concerned with the highest intellectual integration.

I think that it is even possible that the continued bombardment of the unaffected hemisphere by such unruly elements is capable of inducing secondary epileptogenic foci. Support is given to this contention by a study of case records, particularly those of Case 3 and Case 9, in which there were frequent petit mal episodes before removal of the hemisphere. In the past many of our clinical deductions regarding localization and function in the central nervous system have been based on the concept of non-function and negative activity of areas of pathology, and due regard has not always been given to the fact that these areas may often be the site of increased, albeit distorted activity ; in other words, zones of dysfunction rather than of nonfunction. At operation electrocorticograms have been recorded, and are included later with the individual case reports, together with photographs of the brain with markers in position indicating the regions from which bipolar recordings were made. It will be seen that zones far removed from the site of macroscopic pathology are often those showing the greatest dysrhythmia, and it was this fact which first led me to remove the entire hemisphere in these cases.

\section{Case Reports}

Case 1 (Serial No. 1624, A. H., Female).-This child was brought to me on January 16,1945 , at the age of 9 years. There was a story of prolonged, difficult 
labour. The following is a letter from the child's mother when she made the appointment two months earlier. It is such a good presentation of the case, that I take the liberty of setting it down in place of my own routine history.

“ Dear Doctor,

My little girl aged eight years was injured at birth by forceps. The injury was over the left eye, and, I was told, would cause no trouble. However, three days after she was born, she developed a jaundiced condition, had a collapse, and became slightly paralysed on the right side. She was given calcium and recovered, but has grown up with her right side affected. At first I considered it only a physical injury. She drags the right foot slightly and leaves her right arm hanging unnaturally, and her right eye droops. Now, however, I realise that her brain too is affected. She is liable to go into unreasonable and unmanageable tempers, and lacks the power to concentrate, and she has had mental lapses and rigors which I am told are epileptic. I regret I was not told the birth injury was the root of the trouble. I was given the impression that it was a physical fault on my part and have had no other children.'

The child had been placed in an institution because of the temper tantrums and irritability which made discipline impossible.

In the past 18 months she had developed mental lapses in which there occurred grinding of the teeth, talking complete nonsense, uncontrolled shouting, and the uttering of queer noises lasting from one to two minutes. Mentally she was slow and backward, and had not learned to write or read.

On examination, the cranial nerves did not show any deviations worth recording, the optic discs were of normal appearance, and the visual fields were full.

The right arm was shorter and less well developed than the left: posture was typically hemiplegic, tone was increased, and purposive movements exhibited a gross athetoid component. The right lower limb was shorter than the left, with slight equinus deformity and tone about natural. There was moderate weakness of distal muscle groups, both dorsi and plantar flexors. Gait was clumsy. The tendon reflexes were brisker in the right upper limb than on the left, but about equal on both sides in the lower limbs. Abdominal reflexes were all present. No significant loss was encountered for any of the sensory modalities. Ventriculography was carried out and showed a large porencephalic defect situated in the posterior half of the left hemisphere (Fig. 2).

Operation (February 9, 1945, Hemispherectomy).-On coming round from the anaesthetic the child was able to move the right arm and leg as well as before operation, but she now exhibited a right facial weakness. She was allowed up on February 21, and was discharged from hospital on March 10 . It is noteworthy that during the post-operative period she was sweet tempered and cooperative : " altogether a different child". Her mother had taught her the alphabet, and within three weeks of operation she was reading and understanding simple sentences such as "The cat sits on the mat". She was also making progress with her first steps in writing, e.g. making pot hooks, and printing, with the left hand. The most important feature was that she exhibited a desire to apply herself to these matters. I last saw the child on January 13, 1949, and the following is an extract from my follow-up note :-

Follow-up Note.-This child is now 13 years of age. She is rather stout. Her mother tells me that her periods started about one year ago and these are quite regular. With regard to the mental state, she has been at school for about two years, and is in Standard 3,

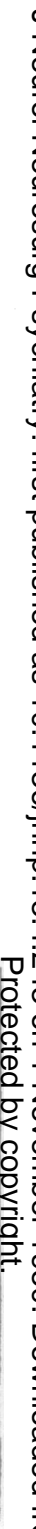

Fig. 2 (Case 1. A.H.).-Ventriculogram. Antero-posterior and right lateral. (Negative touched up.)

that is, she is in a class with children about 10 years of age. She is good at some subjects, particularly history ; arithmetic is weak, but reading and writing she seems to have mastered all right, although she is not reading for her own pleasure.

With regard to her conduct, her mother tells me that her association with other children is entirely normal ; she is at a boarding school for normal children and likes it. Owing to some clumsiness of the right arm she is not partaking in general sport, but she is good at swimming. With regard to memory, she has a good retention of poetry. There has been no evidence of further attacks, or any of the emotional outbursts 
which were the main presenting features when I first saw her. Her span of attention is good; she is an excellent witness, and cooperates well throughout the examination. In attitude she is a little shy and reserved during the first few minutes of the consultation, but soon settles down to a normal approach. General health has been good. The mother has become aware of the right homonymous field defect, and tells me there is sometimes a drooping of the right eyelid. Extreme ocular movements are not quite perfect. Her walking is now nearly normal, and any disability that there is is not due to spasticity, or an athetoid element, but due to a relative slight shortening (about $\frac{1}{2}$ in.) of the right leg, with a slight shortening of the tendo achillis and some degree of pes equinus.

Neurological examination reveals a right homonymous hemianopia with macula sparing, and the fundi are somewhat pale. The corneal reflex on the right is not so brisk as the left, but pin prick and cotton wool are normally appreciated in the trigeminal field on both sides. There is no facial weakness. The tongue protrudes normally. Her speech is a little slurred ; this has always been so, and her mother tells me that in the home circle this entirely disappears.

There is a slight relative shortening of the right upper limb compared with the left, but this is less noticeable than it was originally, and the muscle bulk is good. There is still weakness of extension of the wrist ; flexion is good and equal on both sides. Tone is perhaps slightly increased in the flexor muscles of the wrist. Reflexes of the right arm are only slightly increased as compared with the left. She is not using the right arm too well, as, for instance, when she is dressing herself, tying her shoelaces, fastening a buckle. Posture is equally maintained on both sides. In the finger-nose-finger test there is now only a small residue of the gross spastic athetoid element which was there before operation.

In the lower limb power is good and equal in all muscle groups, except for some resistance of dorsiflexion of the right foot as a result of a slight contracture of the achilles tendon as noted above. Purposive movements in the lower limbs are very accurately carried out, and the "heel-knee-shin" test was faultless on both sides. The muscle bulk is good and equal, and although there is shortening, this is now relatively less than it was four years ago. In the lower limbs the reflexes are about equal, and somewhat brisk on both sides. The right plantar is still extensor, and on the right, the abdominal reflexes, although present, are slightly less brisk than on the left.

Pin prick and cotton wool are equally well appreciated over all areas of the body, although on the first testing she thought it was perhaps a little sharper on the left than on the right, but later was quite certain that this was not so. Joint sense was carefully tested in the fingers of both hands, and at the wrists. She made several mistakes, about three out of ten in the right index finger and more mistakes for the little finger, on the right side, whereas the left was absolutely accurate. Wrist movements through a small range were equally appreciated on both sides; two point discrimination, thenar eminence, $1.2 \mathrm{~cm}$., occasional mistake right side, accurate on the left. With eyes closed she had difficulty in finding the right forefinger with her left hand, but was very accurate in finding the left forefinger with the right hand. Localization of pain and touch was accurate on both sides.

Case Comment.-A year has passed since this note was made, and I have not had the opportunity of seeing the child again. Her mother tells me that she continues to make satisfactory progress in all spheres, and that she still remains free from any fits, five years after operation. It is to be noted that she has not received anticonvulsant sedation since operation.

Case 2 (Serial No. 2832. C.M., Female).-The patient was born at full term and instruments were used. According to the father the child was perfectly normal and healthy until the age of 2 years, when she suddenly had a convulsive episode which resulted in paralysis of the right arm and leg. After six weeks power started to improve, but she was left with a clumsy weakness of the right side. Three years later, at the age of 5, she started having fits. The father said that the fits came on without apparent warning, and that consciousness was lost, the eyes turned up, and the legs were twitching. Since the age of 5 years she has been having fits almost nightly, and as many as 12 during a 24-hour period. Uncontrollable emotional outbursts and destructive tantrums were frequent events.

On questioning the child said that she usually knew when an attack was coming on. She would have a feeling of fear and depression, and she would then feel her right arm beginning to pull upwards.

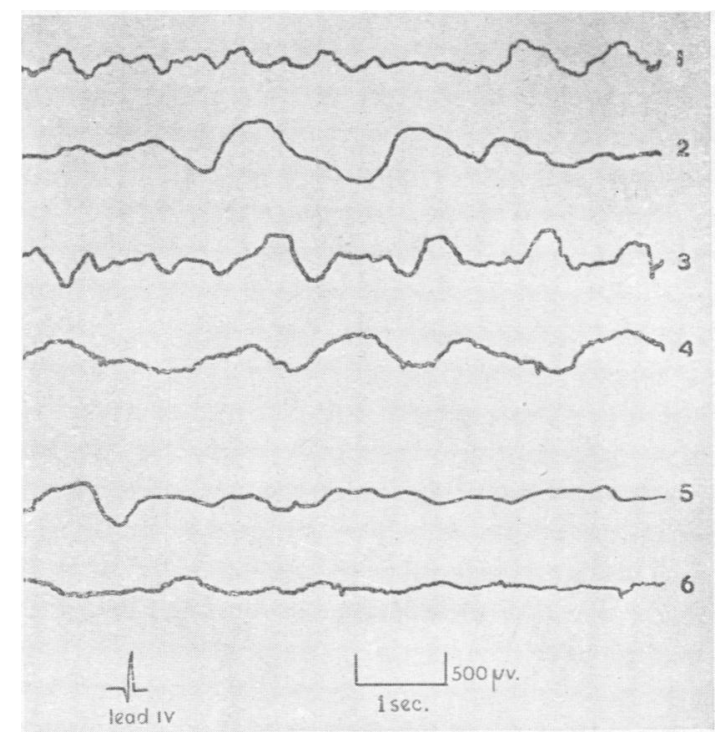

Fig. 5 (Case 2. C.M.).-EEG tracings at op zrat ion. 


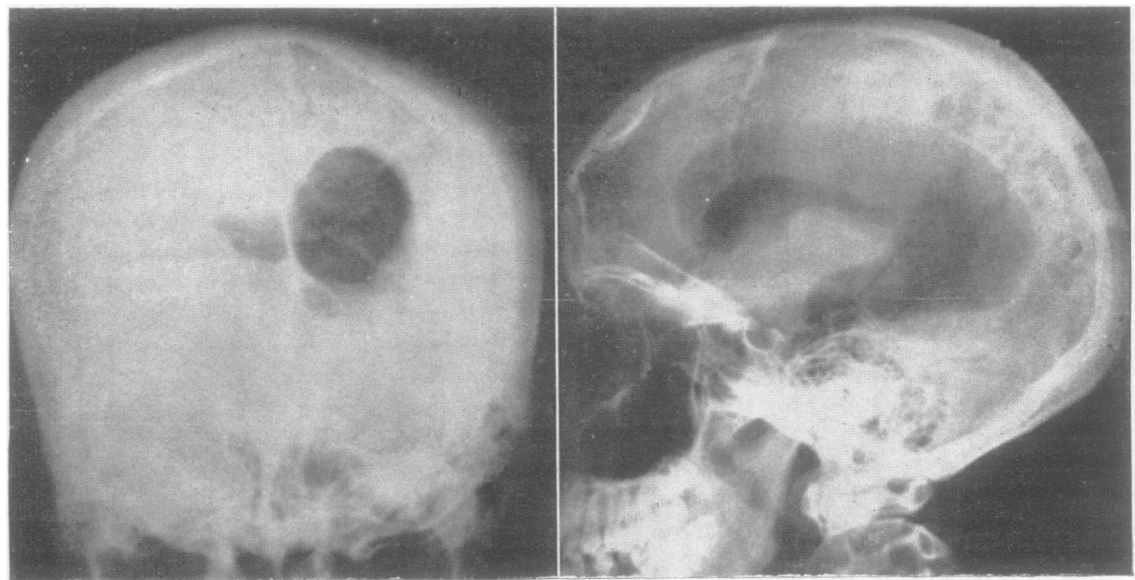

FIG. 3

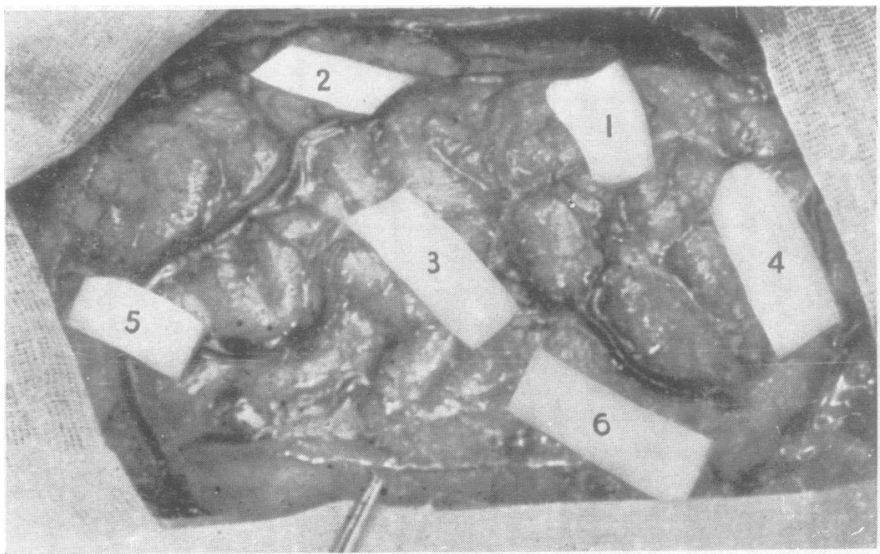

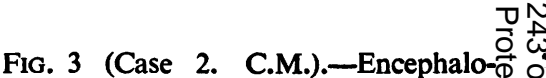
gram: antero-posterior and righn lateral.

륵

Fig. 4 (Case 2. C.M.).-Cortex ex- 웅 posed at operation. EEG markerso $\frac{\mathbb{D}}{3}$ in position.

Fig. 4

Fig. 6 (Case 2. C.M.).-Motor cortex as determined by stimulation.

Fig. 6

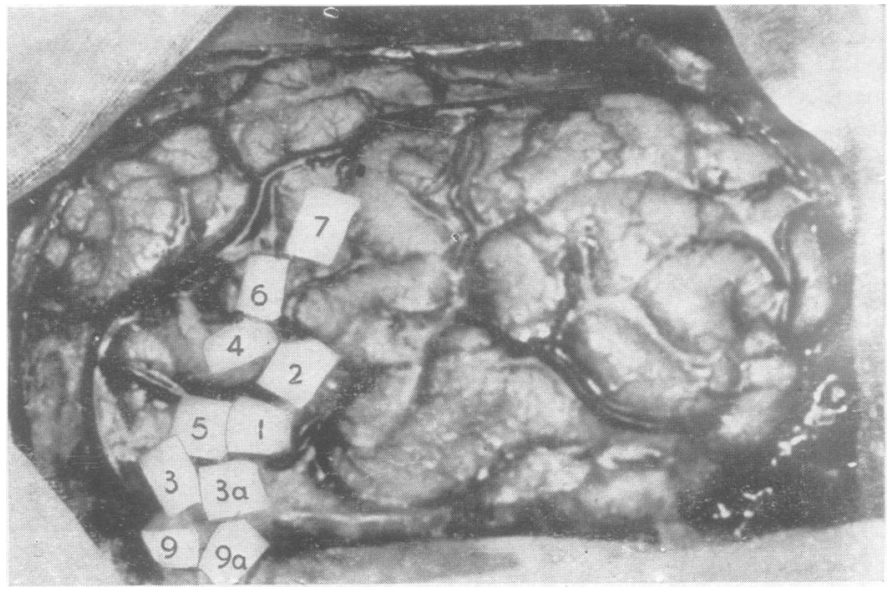


The father said that she never used the right arm or rand, and that she dragged the right foot and walked with a limp.

The child exhibited a marked and irritating restlessness, and it was impossible to hold her attention for more than a few seconds.

There was no disturbance of the language function but her vocabulary was very limited. Schooling had been attempted with little result.

The visual fields were full to confrontation tests, and the fundi were of normal appearance. There was no facial weakness, and no abnormality was detected in examination of the other cranial nerves. The right arm and hand were found to be much smaller and shorter than the left, with the limb adducted, the elbow flexed, the wrist dropped, and the fingers extended and flaccid, whereas the rest of the limb was rather spastic. Purposive movements showed a marked athetoid clumsiness. Tendon reflexes were all brisker on the right, the abdominals were present, and the plantar response was of the extensor type on the right side. Pin prick and cotton wool were normally appreciated throughout. Considerable loss of joint sense in both the hand and foot on the right side was present. Air encephalography was carried out, and showed a gross dilatation of the lateral ventricle on the left side (Fig. 3).

Operation (June 20, 1947, Hemispherectomy).-The convolutions of the promotor and motor areas were rather narrow and felt leathery to the advancing brain needle. The frontal pole was also of a rather tough consistency, but posteriorly in the parietal and occipital zones the brain had a more normal feeling, but the convolutions were rather wide and flattened, and perhaps somewhat pale, quite unlike those anterior to Rolando. Bipolar electroencephalographic recordings were taken from the positions indicated in the operation photograph (Fig. 4) which shows the markers in position. Fig. 5 shows the EEG recordings taken from these positions.

Thyratron stimulation was also carried out and the motor cortex mapped out as shown in Fig. 6.

The day after operation it was noted :

"She is drinking and swallowing well and passing urine normally. There is some movement of the right arm, which is spastic. The right leg is atonic, but the movement is good."

On July 10, 1947, there is the following note in the records :

"She is doing occupational therapy in order to train her right hand to greater advantage." By August 8 her walking was " quite good ", and she could extend her wrist slightly. A letter from C. M.'s father, dated February 14, 1949, states.

" ...... I am pleased to tell you that she is in perfect health. Mentally there is a big improvement. There are no signs or symptoms of the fits returning and she seems to be more balanced and contented in her mind. $\mathrm{C}$ is still, however, more childish in her outlook than her age would indicate, probably on a par with a child of ten, which does not mean to say that she is stupid. Her appearance is quite normal and bright. Unfortunately her hand and leg are still showing no signs of improvement; they are as before, but she is very active and tries to use her hand sometimes."

Case Comment.--I last heard of this child in January 1950, two and a half years after operation. Mentally she continues to make marked and gratifying improvement. She mixes well with other children; she is tractable and well balanced, and exhibits none of her former emotional outbursts. There have been no further fits since operation. No sedative medication has been given her.

Case 3 (Serial No. 3331, W. O., Female).-This child was first seen on February 10, 1948, aged 3 years. She was a premature infant. The mother's pregnancy and confinement were normal. Development appeared to be normal up to the age of 10 months, by which time the child had started to crawl and to use a few words. At this stage she developed a febrile illness in which a squint of the right eye and paralysis of the right arm and leg were noted. Some power returned to the limbs and the child was able to walk in due course, but with difficulty, and she did not regain the voluntary use of the right upper limb. In February, 1947 , one year before examination, right-sided epileptiform seizures developed. These occurred daily without loss of consciousness. The child's speech did not develop normally; and at examination her vocabulary was limited to three words, "Mama", "Baba", "Ta-ta". The child was obviously grossly mentally retarded. She cried a great deal and became very noisy for no apparent reason. The fontanelles were closed and the head of average size. There was a suggestion of a visual field defect but this could not be checked. There was a mild bilateral ptosis. Otherwise, as far as examination was possible, no anomaly could be detected in the cranial nerves. There was a spastic paralysis of the right upper limb, the growth of which was markedly retarded. The growth of the right lower limb was retarded and there was less spontaneous movement than in its fellow. There was a right pes equinus deformity. The tendon jerks were increased on the right side, the right abdominal reflexes were absent, and the plantar response was extensor. The gait was grossly unsteady and reeling. Air studies were carried out and showed a considerable dilatation of the left lateral ventricle (Fig. 7).

Operation (April 19, 1948, Hemispherectomy).Fig. 8 shows the exposed cortex with markers indicating points from which bipolar EEG recordings were taken. The EEG tracings are reproduced in Fig. 9.

The entire left hemisphere, with the exception of the thalamus, caudate nucleus and its tail was removed. It was interesting to note that thyratron stimulation produced no movement in this case, so that there was no direct evidence of functioning motor cortex. Immediately on regaining consciousness it was evident that the movements in the right leg were not impaired. The post-operative course gave no reason for undue anxiety. Movements in the right upper and lower limbs disappeared on the first post-operative day, the limbs on the right side becoming spastic. The child was parti- 


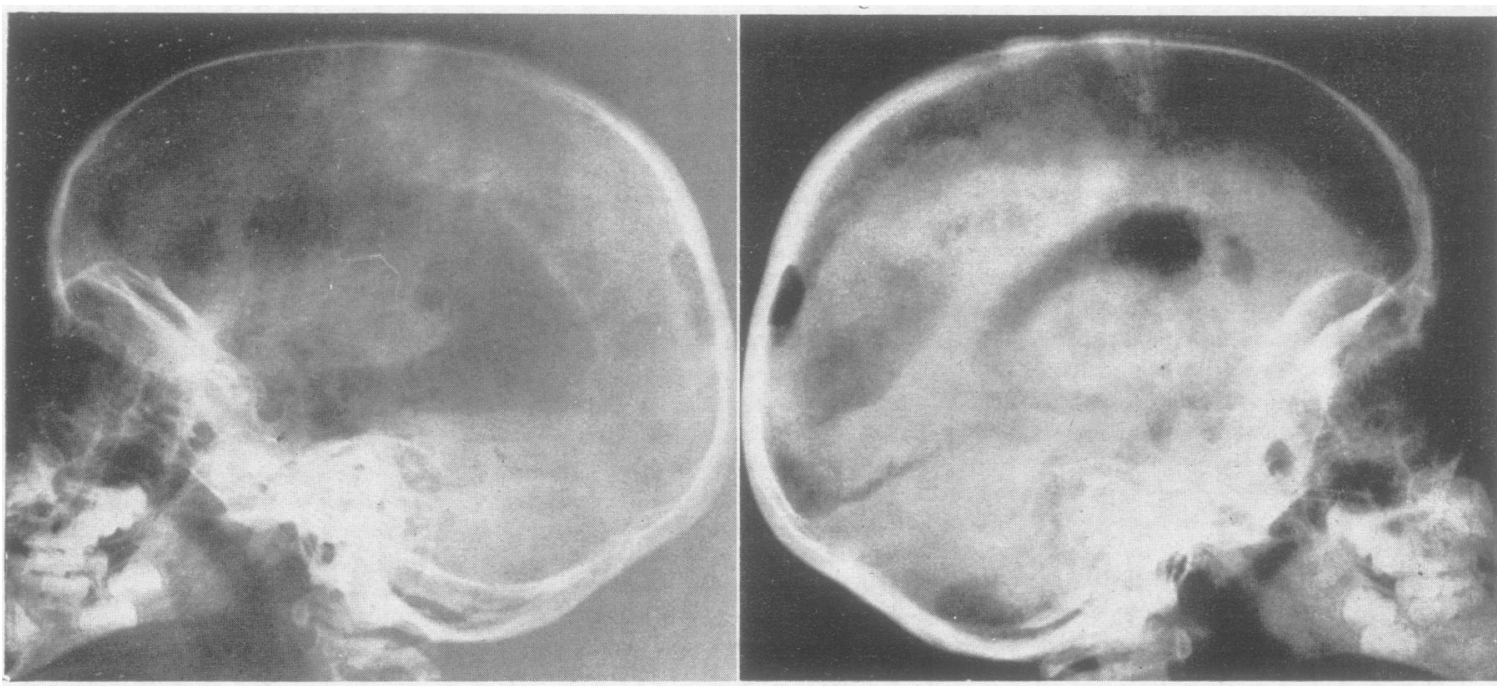

Fig. 7

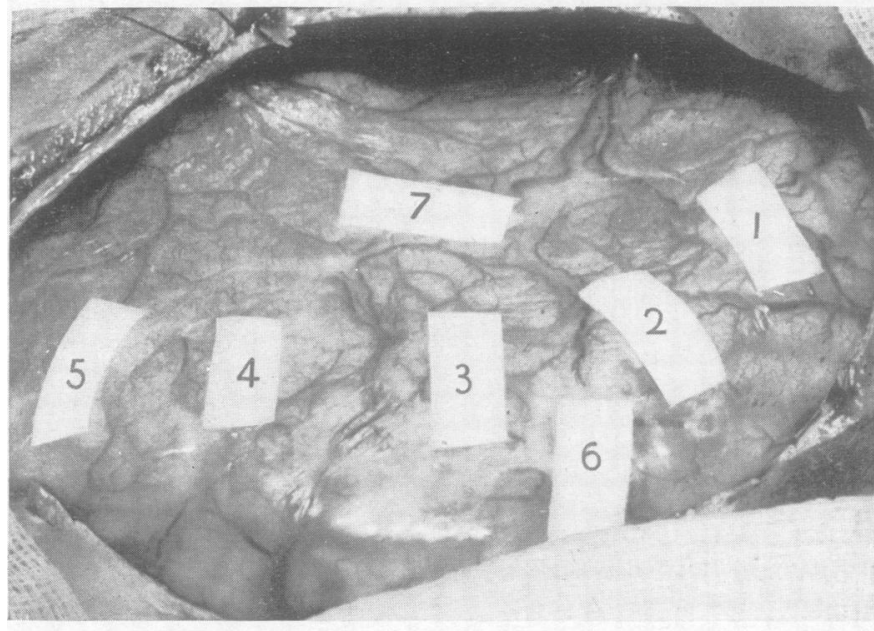

Fig. 8

Fig. 7 (Case 3. W.O.).-Air studies right and left lateral.

Fig. 8 (Case 3. W.O.).-Cortex exposed at operation.

FIG. 9 (Case 3. W.O.).-EEG tracings at operation.

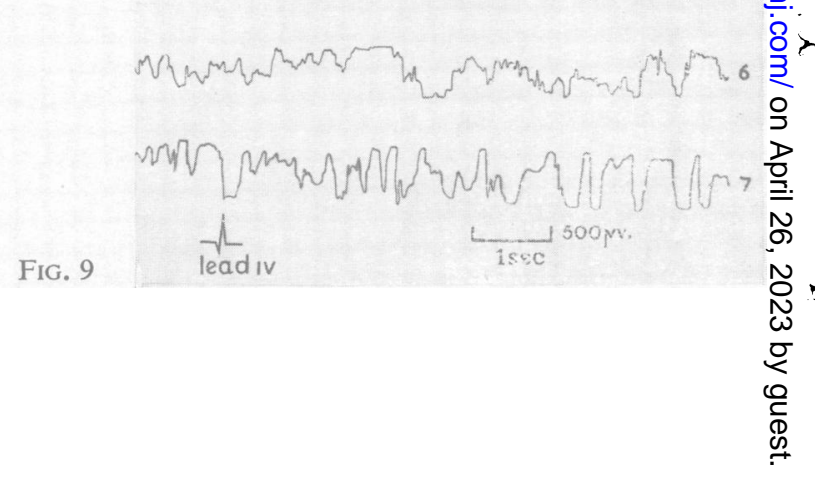


cularly apathetic for the first 11 post-operative days, and it may well be that this was the cause of the apparent inability to move the right-sided limbs.

On May 5 movement of the right lower limb returned and the child took more interest in her surroundings and responded to attention. By May 12 she was playing with her toys and was greeting the attendants with a cheerful smile. By May 17 the head wound was well healed. The child was attempting to express herself by making peculiar little noises which were, however, quite unintelligible. She was particularly bright and happy and taking a lively interest in her surroundings. There was some movement of the right upper limb and the movements of the right lower limb were maintained. Movements were mainly in the proximal parts of the limbs, but there were no voluntary movements of the hand or foot.

On May 24 physiotherapy was begun. The child was discharged from hospital on June 10. It was thought at the time that there had been a considerable improvement in the mental sphere since operation. She was much more responsive, was paying more attention to her toys than before operation, seemed to be attempting to form words, and the bouts of noisiness and crying were no longer present. When she left hospital on June 10 there were still only slight shoulder and thigh movements on the right side. The upper limb was still more spastic than the lower; the reflexes remained as before operation. There had been no epileptiform seizures since operation.

The child returned on August 14, 1948. We were all delighted at the progress shown. She was walking and running, although the right lower limb was still spastic and showed a fixed equino-cavus deformity. Balance appeared to be perfect ; movements of the right upper limb were still minimal. The father expressed the deepest pleasure at the child's progress. There had been no seizures since operation and the child had remained consistently sweet tempered. The vocabulary had extended considerably and the child appeared to be progressing very rapidly in the mental sphere; she could understand commands and carried them out properly.

Case Comment.-The child was seen again in November, 1949, and one was struck by her remarkable growth and general physical development. The spastic disability of the right arm and leg was considerable, although she was walking well and attempting to use the right hand. Her understanding of the spoken word was excellent, and speech was surprisingly good; she prattled away in the manner one would expect of any child between the age of three and four. There have been no further fits or suggestive episodes.

Case 4 (Serial No. 2582, R. v.d. V., Male).-The boy, aged 10, was admitted on January $27,1948$.

A few days after a normal birth, the infant became very ill and weakness of the limbs on the right side was noticed. This was accompanied by convulsions. The child was speaking at one year, and walking at 17 months. His mentality subsequently appeared to be below average. Petit mal episodes began two years before examination, and were increasing in frequency. He had also developəd episodes, preceded by complaints of epigastric pain, in which the eyes became set and the right hand was drawn up and remained fixed for a second or two. The hemiparesis of the right side persisted.

On examination, the positive findings included a right homonymous hemianopia, external divergent strabismus, a right-sided facial weakness of the upper motor neurone type, right spastic weakness of the arm associated with athetoid movements, and spastic weakness of the right leg. The limbs on the right side had lagged behind in growth. There was gross impairment of three-dimensional sensation on the right side. The child was left handed and showed. a distinct tendency to "mirror writing"; for this. reason he had great difficulty in school. He displayed an endless drive to activity which manifested itself in the performances of numerous drawings and paintings, which showed a good colour sense, a general appreciation of form, but a lack of appreciation of the relative position of the main objects represented. EEG showed generalized non-specific dysrhythmia, and a large area overlying the left occipital and parietal regions from which there was little or no activity (Fig. 10).

Air studies revealed a large, left-sided porencephalic defect, occupying the posterior half of the left hemisphere (Fig. 11).

Operation (March 22, 1948, Hemispherectomy).EEG records were taken from the exposed cortex (Figs. 12 and 13). Stimulation and mapping out of the motor cortex was followed by removal of the entire hemisphere, with sparing of the caudate nucleus and thalamus (Fig. 14).

The day after operation no movement was detected in the right arm, which was spastic. There was someslight movement of the right leg. Speaking and swallowing were not impaired. On March 24 movement had returned to the right upper limb. On March 25 movements in the right upper limb were carried out quite well at the pre-operative level, when first asked to do so, but the child found it extremely difficult to repeat the movement more than once in a short space of time. On April 7 the child was carrying on normal conversation. The spasticity of the limbs on this date was noted as being less than in the immediate post-operative phase. On April 14 the child was walking very satisfactorily at a level corresponding with the pre-operative state. On May 10 he was discharged from hospital. At this time he was up and about and played happily with the other children in the ward. Attention was now easily obtained and well held. Comprehension and orientation were unimpaired. Memory appeared to be good for both recent and remote events. $\mathrm{He}$ appeared to have lost his spatial disorientation. He felt that he now appreciated the relative position of objects, and, when in the subsequent months he was kept under observation, it was noted from his drawings that this appaared to be so. The tendency to " mirror writing" was no longer present. He was already aware of a 


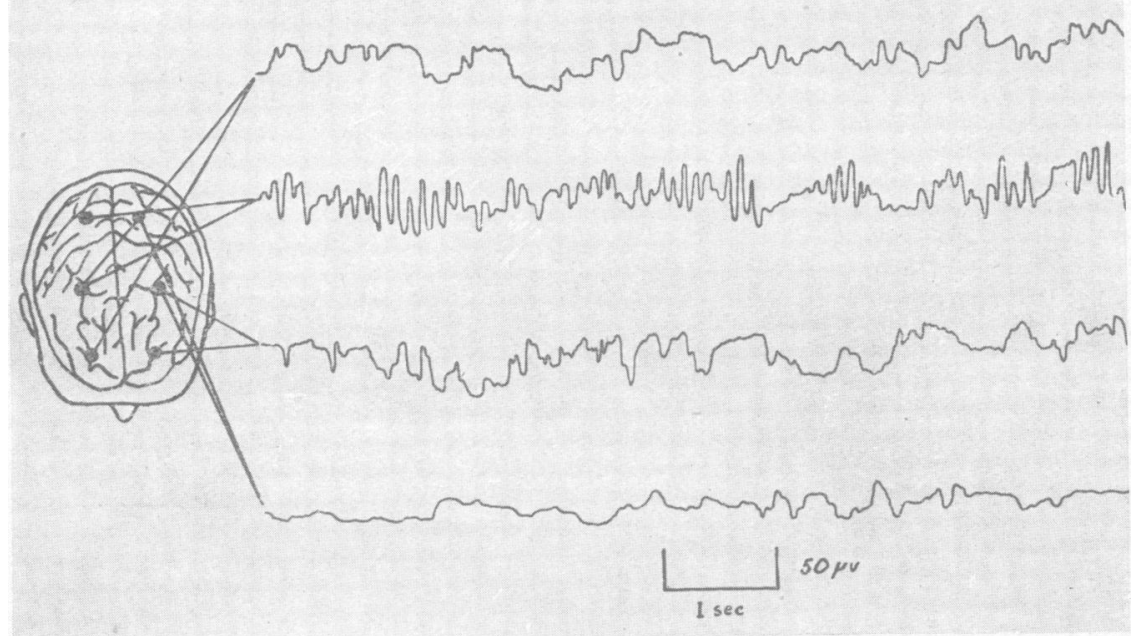

Fig. 10

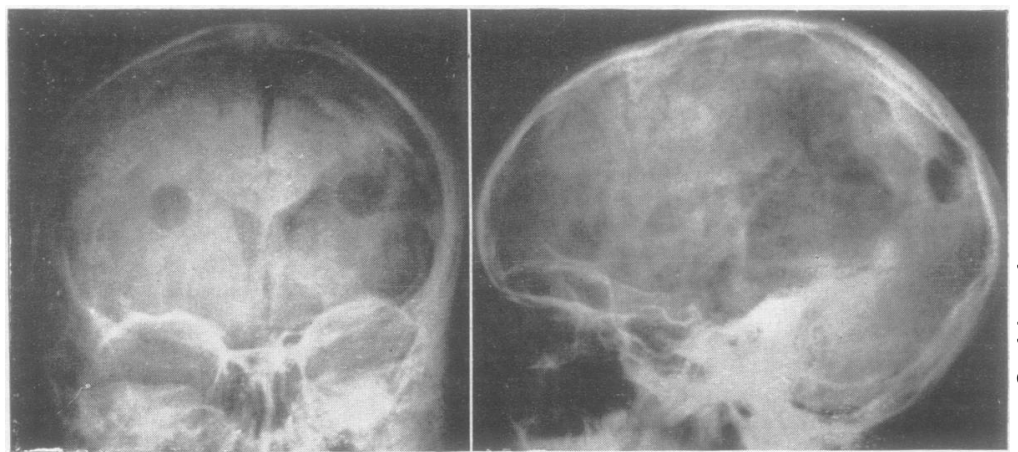

FIG. 11

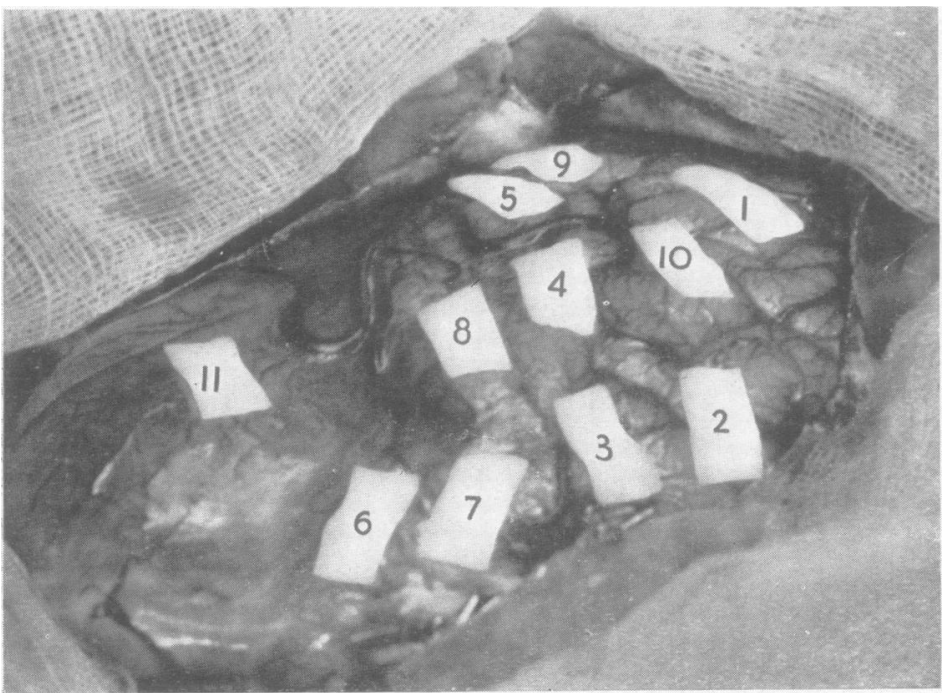

Fig. 10 (Case 4. R.v.d V.).-Preoperative EEG tracings.

Fig. 11 (Case 4. R.v.d.V.).-Ventriculogram: A.P. and right lateral.

Fig. 12 (Case $4 . \quad$ R.v.d.V.).Exposed cortex at operation.

FIG. 12 


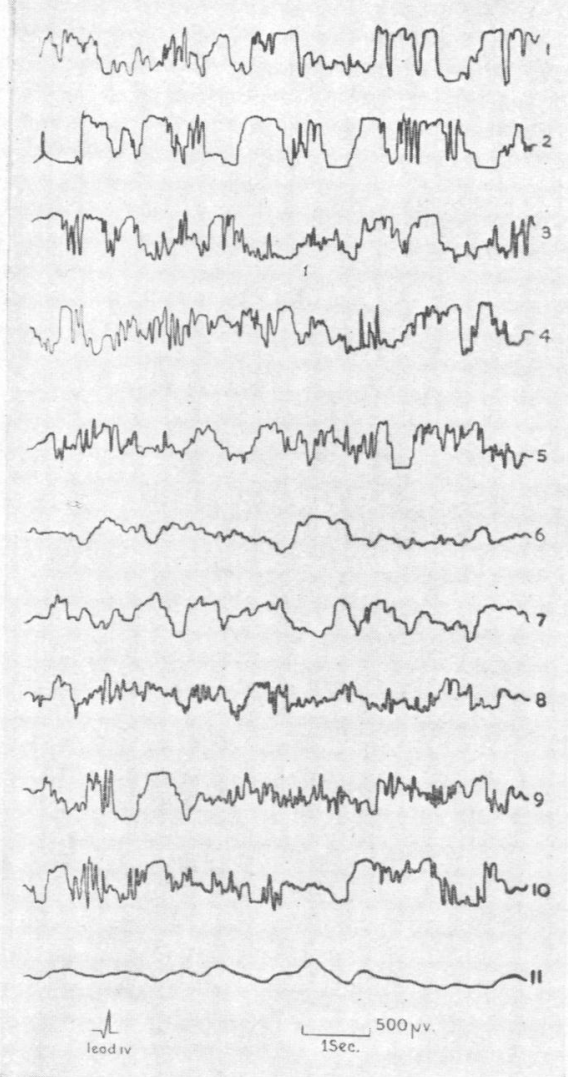

Fig. 13

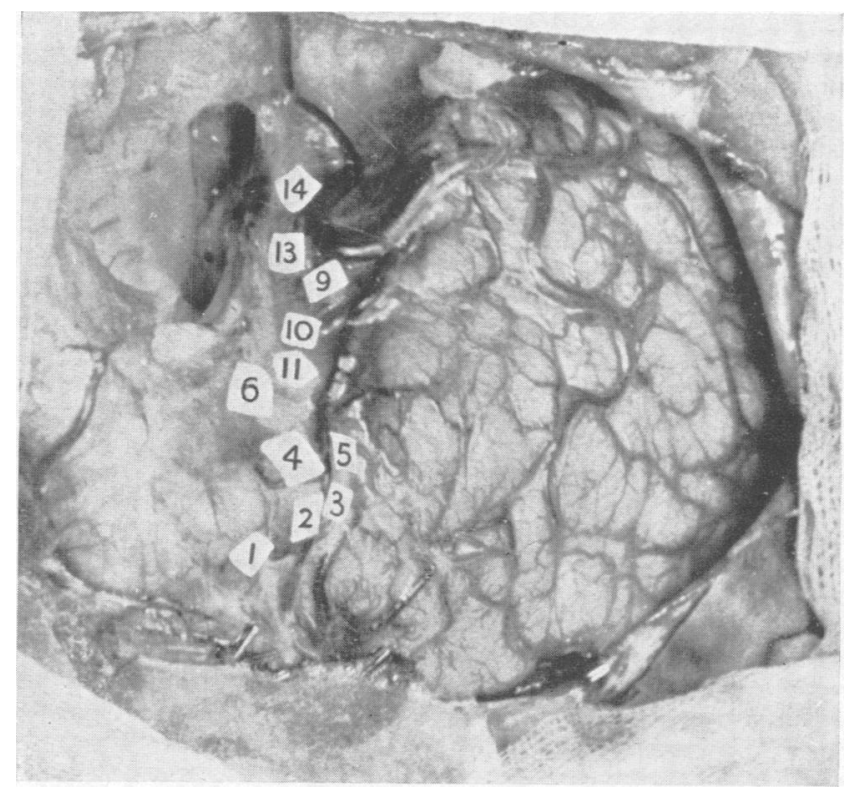

Fig. 14

FIG. 13 (Case 4. R.v.d.V.).-EEG tracings at operation.

Fig. 14 (Case 4. R.v.d.V.).-Motor cortex as determined by stimulation.

Fig. 15 (Case 4. R.v.d.V.).-Post-operative EEG tracings.

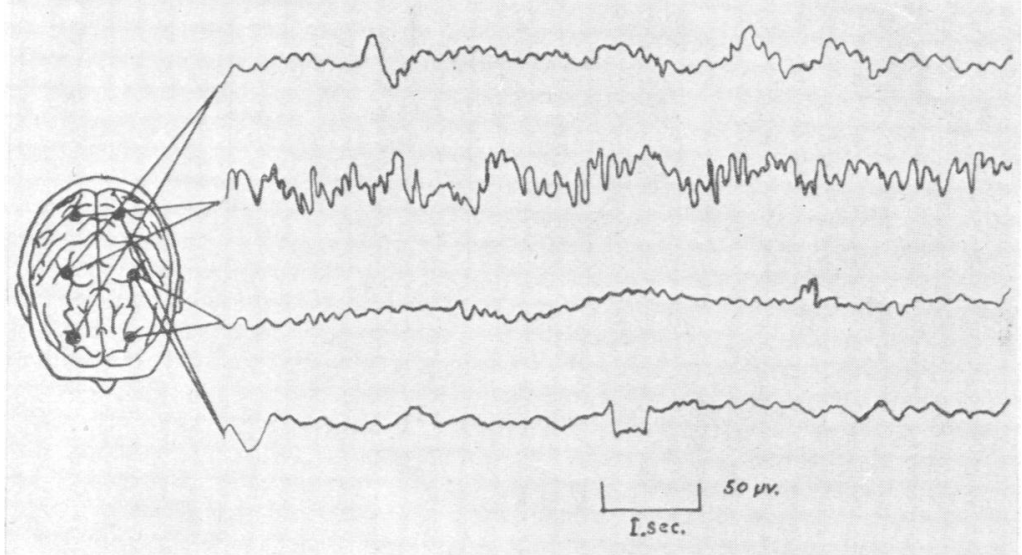

FIG. 15 
great change in his own mental state and discussed his mental outlook as compared with the pre-operative state. He said that his right arm and leg were less stiff and more easily controlled than previously. He no longer felt restless, but would concentrate for any length of time on matters which interested him, such as drawing and painting. He admitted that before the operation he would have uncontrollable urges to do naughty things, that he could not and did not want to learn, and that his mind never seemed to settle. Now, after the operation he no longer felt restless, was interested in his painting, and wanted to improve his art and was

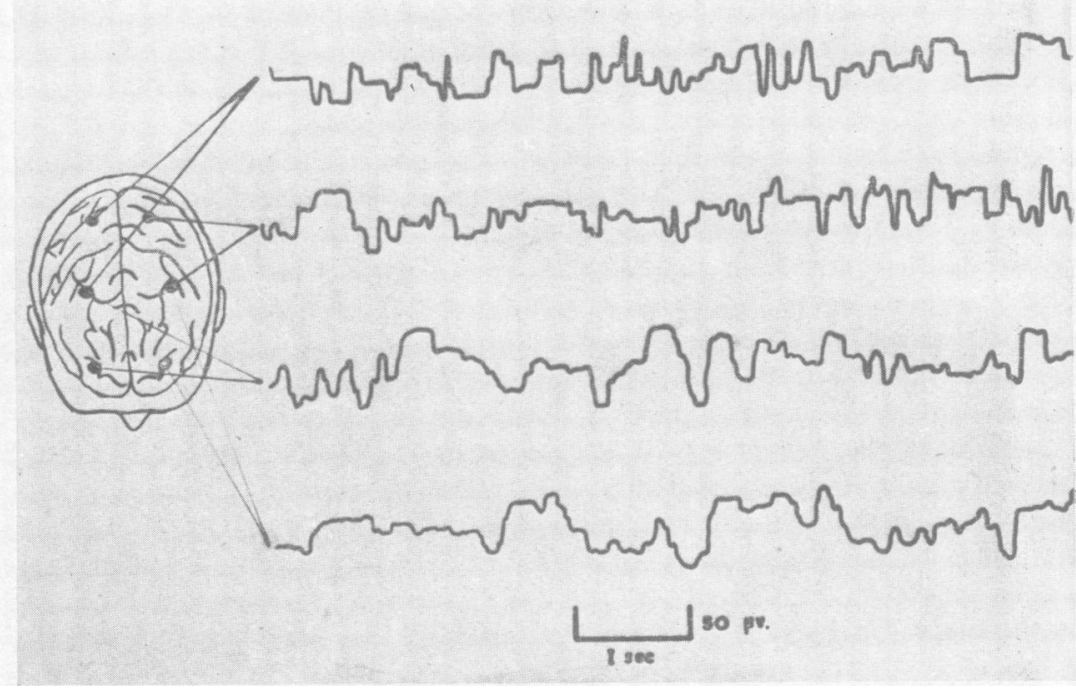

FIG. 16 (Case 5. Miss A.).-Pre-operative EEG tracings. keen to proceed with his schooling. His parents supported all this and said he was no longer just a difficult child, but an interested and interesting member of the household.

Case Comment.-I have seen this boy at regular intervals; he often comes up to the hospital to talk to us, and to show us his latest drawings. His improvement has been progressive; he is back at school and doing well, and as an artist he is showing great promise. There have been no further fits or petit mal episodes, spasticity in the limbs is lessening, although the shortening and equinus deformity of the right leg and foot constitute a considerable disability. The athetoid component in his purposive movements is now very much less. Pin prick and touch are normally appreciated and
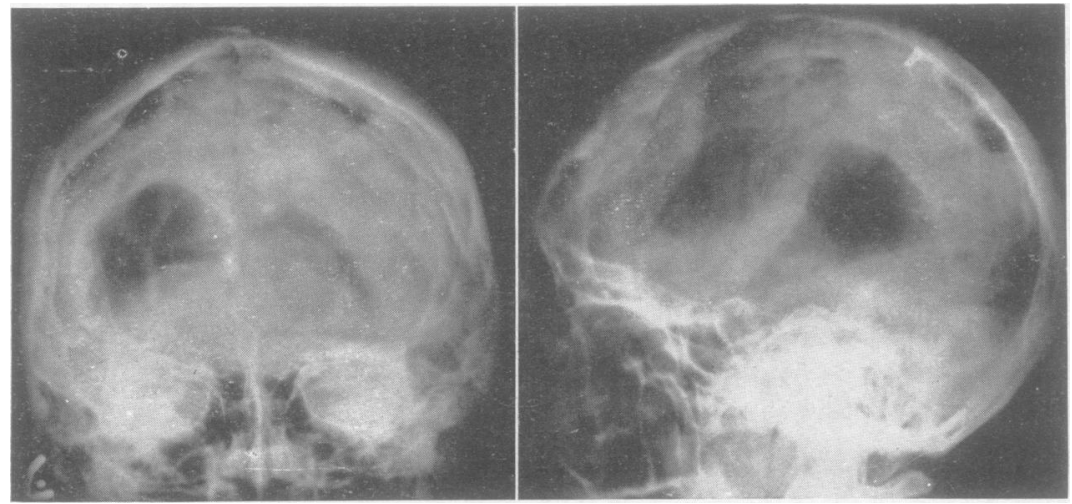

Fig. 17 (Case 5. Miss. A.).-Ventriculogram : postero-anterior and right lateral. localization of these modalities is accurate. Joint sense is considerably impaired in the fingers of the right hand, but is accurate at the wrist. He has a right homonymous hemianopia with macular sparing. The right lower facial weakness is still more pronounced than it was before the operation. An electroencephalographic check-up 12 months after operation showed the responses to be within normal limits (Fig. 15), with no activity on the right side from which the hemisphere had been removed.

Case 5 (Serial No. 3082, Miss A., Female).-This young woman was first brought to me on January 16 , 1948 , at the age of 21 years. There was a story of delivery by Caesarian section, and the infant was born with weakness of the right arm and the right leg which has persisted. Fits started at the age of 9 years. These were of the tonic clonic type, starting in the right arm with spread to the right leg and right side of the face, and occurring at intervals of five to seven days. More recently, in addition she had developed minor episodes during which she felt she was "wearing an uncontrollable grin", and during which there seemed to be a momentary suspension of consciousness. These episodes were occurring several tinies each week.

On examination, the mental age was assessed at 10 years 4 months, and the 


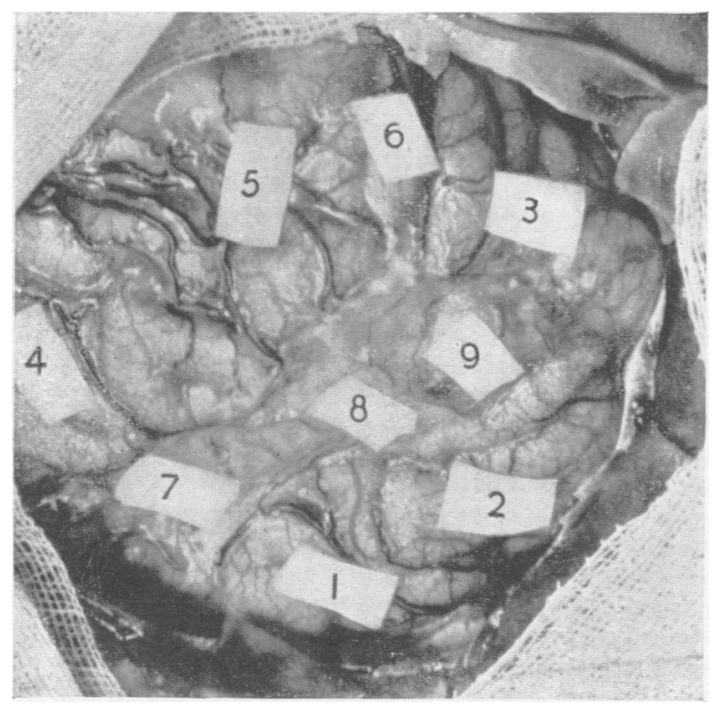

FIG. 18

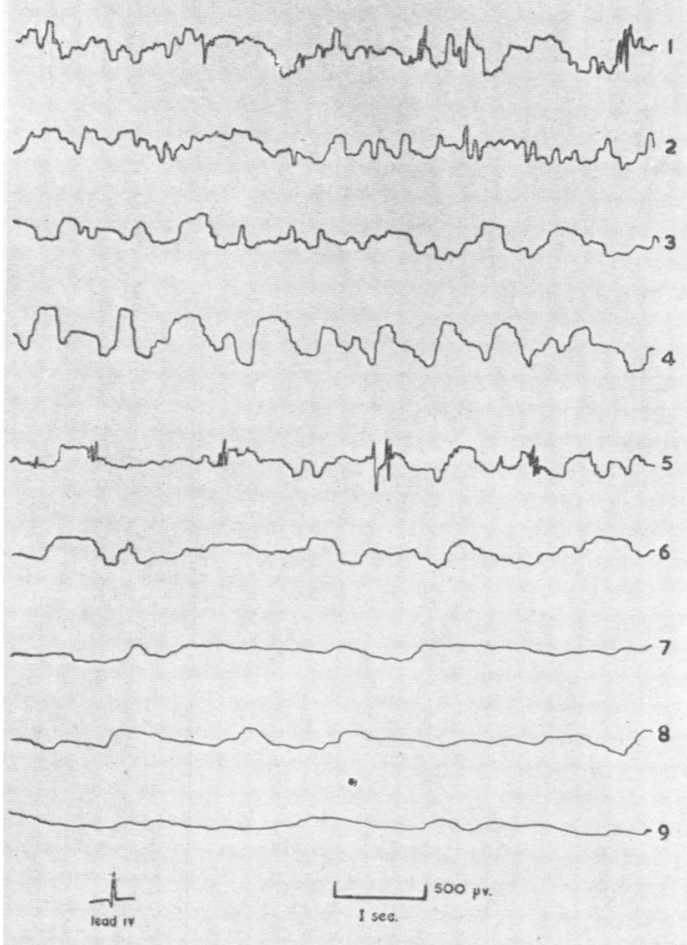

Fig. 19

Fig. 18 (Case 5. Miss A.).-Left hemisphere exposed at operation.

Fig. 19 (Case 5. Miss A.).-EEG tracings at operation.

Fig. 20 (Case 5. Miss A.).-Motor cortex as determined by stimulation.

FIG. 20

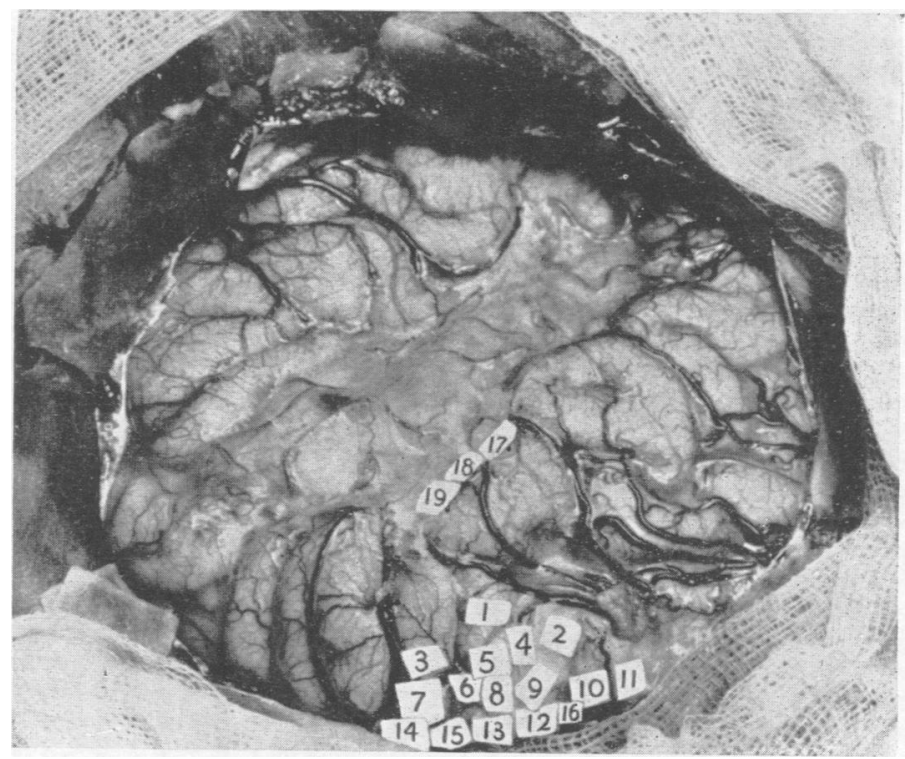


I.Q. at 70. There was no disturbance of the language function. Visual fields were full. The limbs on the right side were shorter and less bulky than on the left, and displayed a spastic athetotic state with increased jerks and extensor plantar response. Joint sense was poor in the fingers of the right hand. There was also inaccuracy of two point discrimination and impairment of vibration on the right side. This girl was unhappy, depressed, and acutely aware of her disabilities. She had no amusements, did not read, and was afraid to mix with other people. She would not go to places of entertainment "for fear of an attack". Her personal appearance meant nothing to her and she states

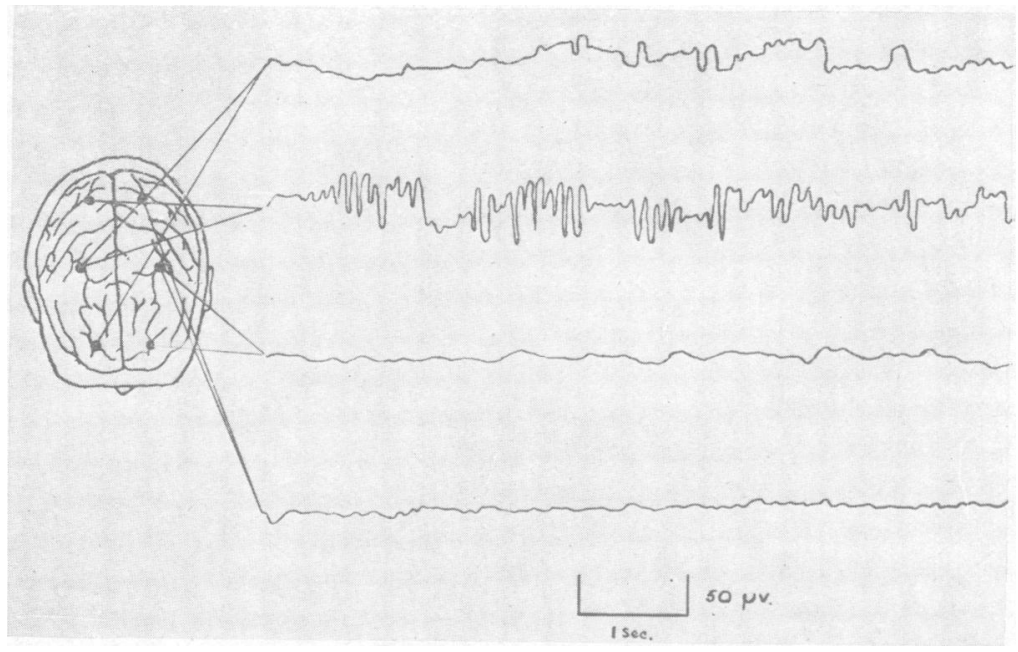

FIG. 21 (Case 5. Miss. A.).-Post-operative EEG recordings. that she had "nothing to live for". The pre-operative EEG and air studies are shown in Figs. 16 and 17.

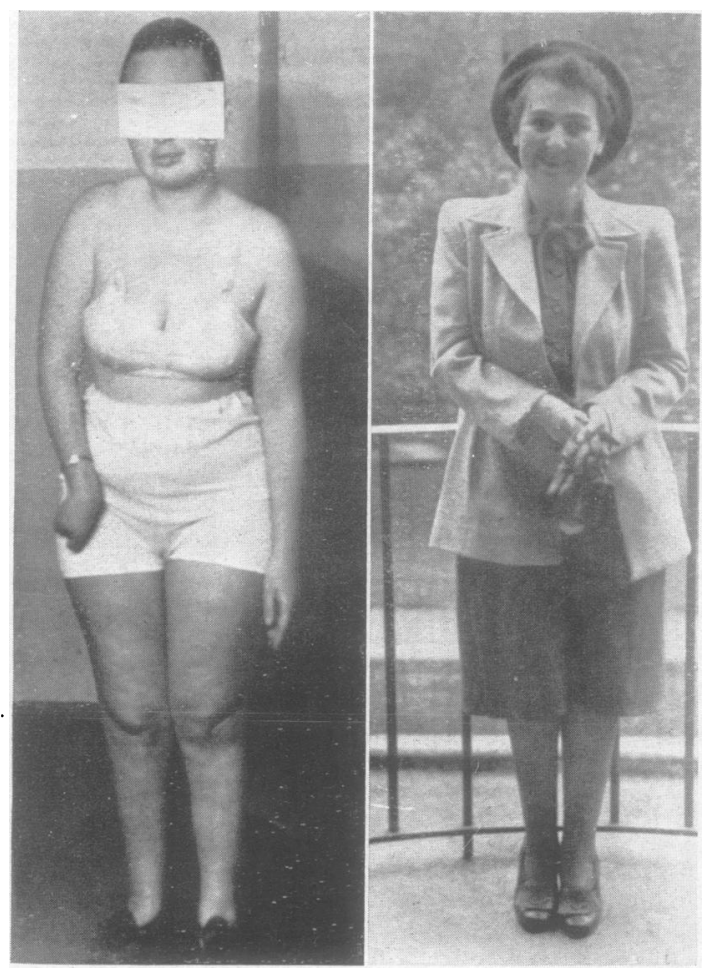

Fig. 22 (Case 5. Miss A.).-Post-operative pictures. Left.-Five wieks after operation. Right.-Six months after operation.
Operation (August 25, 1948 . Hemispherectcmy).After the cortex had been exposed by an appropriate left lateral flap EEG recordings were taken (Figs. 18 and 19).

The motor cortex was mapped out by thyratron stimulation (Fig. 20). This picture also shows the thinned out gliosed cortex in the lower two-thirds of the line of Rolando. The arrangement of the blood vessels is noteworthy, as is the peculiar distribution of stimulable motor area. Complete hemispherectomy, as defined earlier in the report, was then carried out.

By the next day Miss A. was speaking normally, and movement of the affected limbs had returned to the pre-operative level.

Progress in this case ha: been extremely gratifying, and re-examination on February 1, 1949, revealed the facts and impressions which were recorded as follows :

"This girl's general appearance presented a very striking improvement on the pre-operative state. Previously, she had looked years older than her age, and was particularly dowdy and careless about her dress. This morning she was smartly dressed and made-up and appeared to have developed an interest in her appearance. One also gained the impression that she had a certain poise which previously had been totally lacking. In conversation she stated that she had much more confidence in herself than before the operation. Whereas formerly she had tended to avoid company, she now sought out her fellow beings, whose company she enjoyed and with whom she felt more comfortable than previously. She also states that she has developed a lively interest in entertainment, such as the cinema, and feels that her memory and appreciation of current events has much improved. She has taken to reading the newspaper and to general reading for the pleasure of the occupation alone, and is certain she would now be able to learn more easily than formerly. She states that in carrying out occupational therapy she is using the right hand and arm more freely than before, and is 

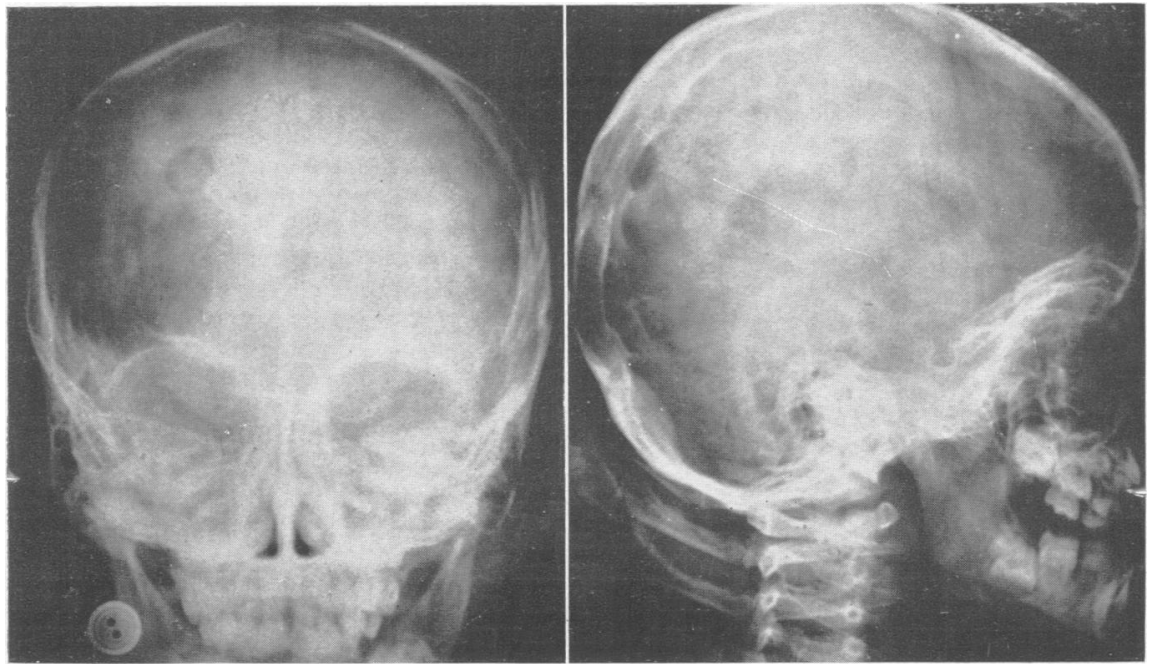

FIG. 23

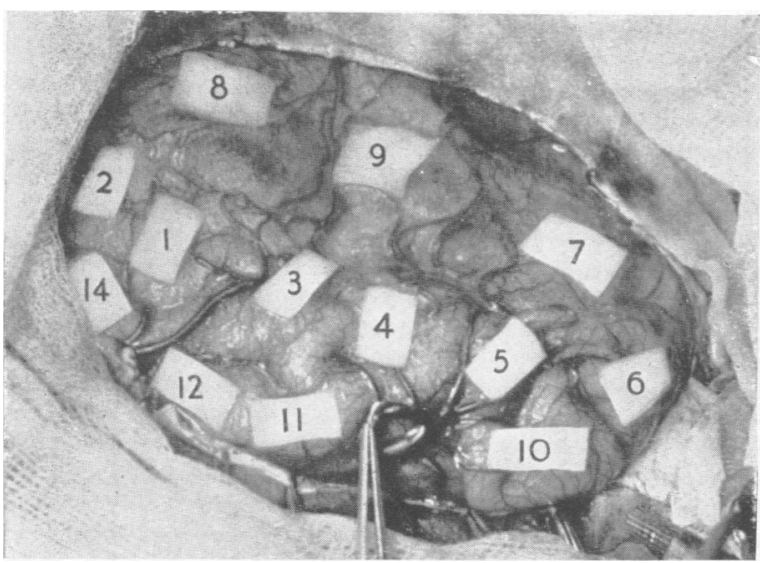

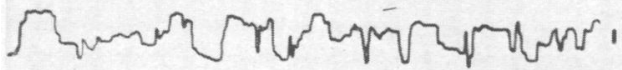

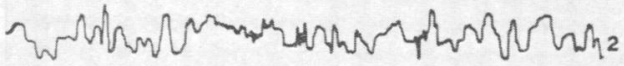

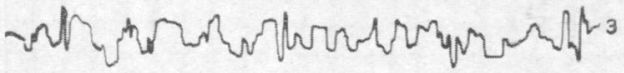

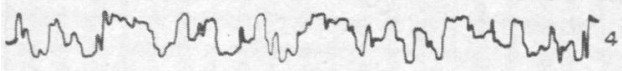

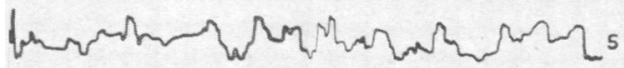

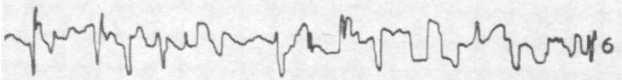

FIG. 24

FIG. 23 (Case 6. Baby S.).-Air studies antero-posterior and right lateral.

FIG. 24 (Case 6. Baby S.).--Exposed cortex at operation.

FIG. 25 (Case 6. Baby S.).-EEG tracings at operation.

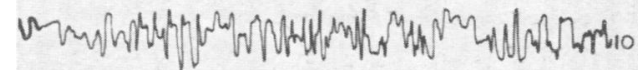

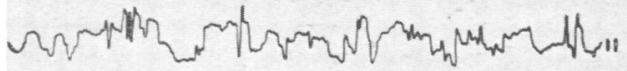

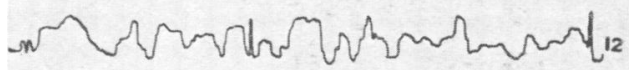

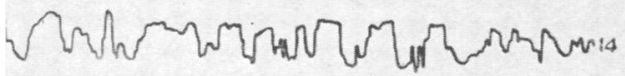

FIG. 25 $\underset{\text { Iead iv }}{\Lambda}$ $\frac{1 \mathrm{sec}}{500 \mathrm{Nr}}$ 
enjoying the work given to her. There have been no seizures of any kind since the operation.

" Neurologically, she had anosmia on the left side, with a right-sided homonymous hemianopia with sparing of the macula. Ocular movements were full and without defect, and there was no facial weakness to be noted. On the motor side there has been a very dramatic alteration in the tone of the right upper limb. In fact, once her confidence is gained, there is no spasticity to be noted at all, although she still tends to carry the limb flexed at the elbow and adducted at the shoulder. One gains the impression that tone is entirely normal compared with the contralateral limb. The fixed deformity at the wrist, resulting mainly from former surgical intervention, complicates the examination, but there is no evidence of spasticity in the muscles acting on this joint. Strangely enough, she does not exhibit a spontaneity of volitional movement one might expect with the general improvement in tone. Movements at the wrist, hand, and fingers, have shown least return to a normal state. There is still accession of flexion at the interphalangeal joints.

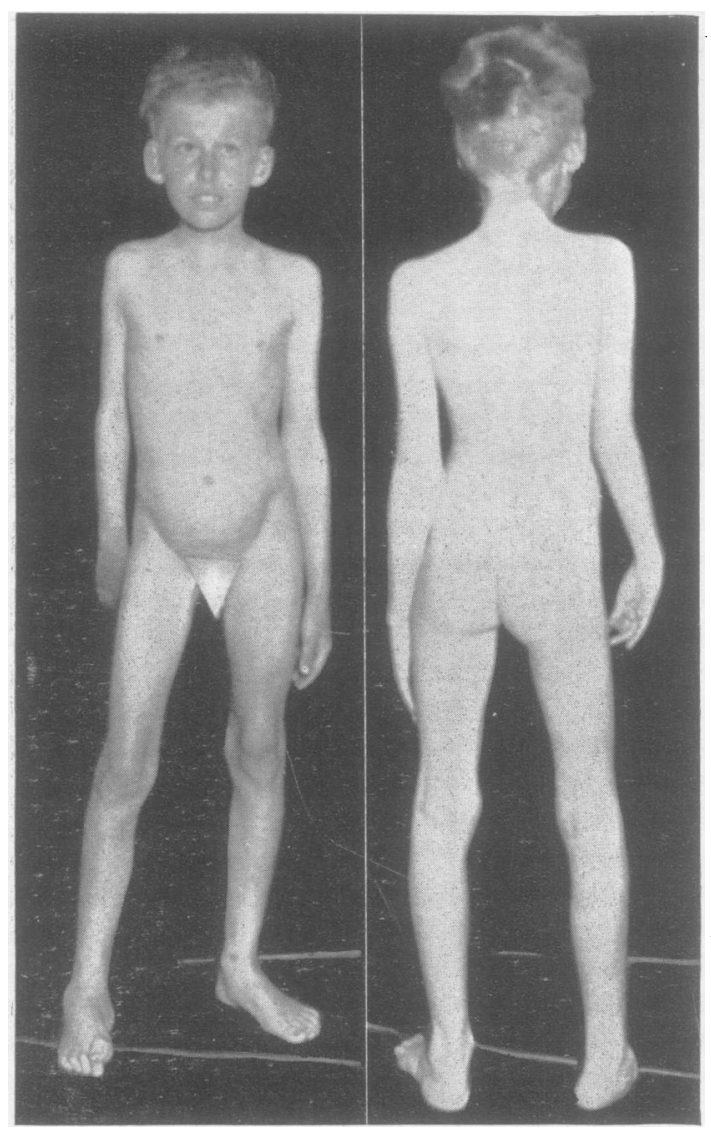

FIG. 26 (Case 7. H.B.).-Photograph 3 months after operation.
There is no forced grasping. Testing of purposive movements in the upper limb shows useful control over the muscles acting on the proximal large joints. There is no gross dysmetria, and no tremor. There is no change in the relative size of the limbs on the two sides. Gait is no longer awkward. Miss A. volunteers the information that she has much greater power in the lower limb, and does not experience her earlier tendency to fall. Tone is still somewhat increased in the right lower limb which still exhibits slight clonus. Objectively tested, power in the lower limbs is good; dorsiflexion at the ankle approximates nearly to that on the normal side.

"In the sensory sphere, there is a lack of ability to localize pin prick in both the affected limbs. It is interesting to note, that whereas she tends to localize pin prick more distally than its actual position, she tends to localize touch with cotton wool more proximally. Vibration sense is still grossly impaired in both affected limbs. Spatial orientation of the affected limb is still poor. She has great difficulty in placing the normal limb in a position comparable with that of the affected limb. The tendon jerks are present and equal in the upper limbs, but in the lower limbs they are brisker on the right side than on the left. It was impossible to study the plantar reflex in this case by the usual method because of the extreme ticklishness of the patient. It $\square$ was interesting to note that the Rossolimo, Mendel- $\bar{O}+\vec{\omega}$ Bechterew, and Hoffmann signs appeared to be negative, $\stackrel{\mathbb{\Phi}}{\triangle}$ but the Oppenheim gave an upgoing toe on the right side."

EEG studies six months after operation showed responses to be within normal limits in the remaining hemisphere, with no activity on the hemispherectomized side (Fig. 21).

Miss A. recently sent me a snap of herself, taken six months after the operation, and this is reproduced in Fig. 22 with a picture taken at the time of the operation.

Case Comment.-The last news I had concerning this patient was in September, 1949, when her uncle, an eminent physician of Capetown, told us at a meeting of the Medical Congress that the results in this case were " nothing short of miraculous". There had been no further fits or minor episodes. Her disposition had become happy and congenial, and above all she was able to hold down a job in an office.

Case 6 (Serial No. 3565, J. S., Male).-This child, aged 2 years 3 months, was first seen by me on May 15, 1948. The confinement had been a short one, and there was no evidence of birth injury. On the thirteenth day after birth the parents noticed that there was something wrong with the left hand, and at one month they noticed that the left leg was stiff, held straight, and that the child would not kick with it. Fits started about the sixth month and have persisted, occurring some six to eight times a day. The parents were not able to give us any information of localizing value 


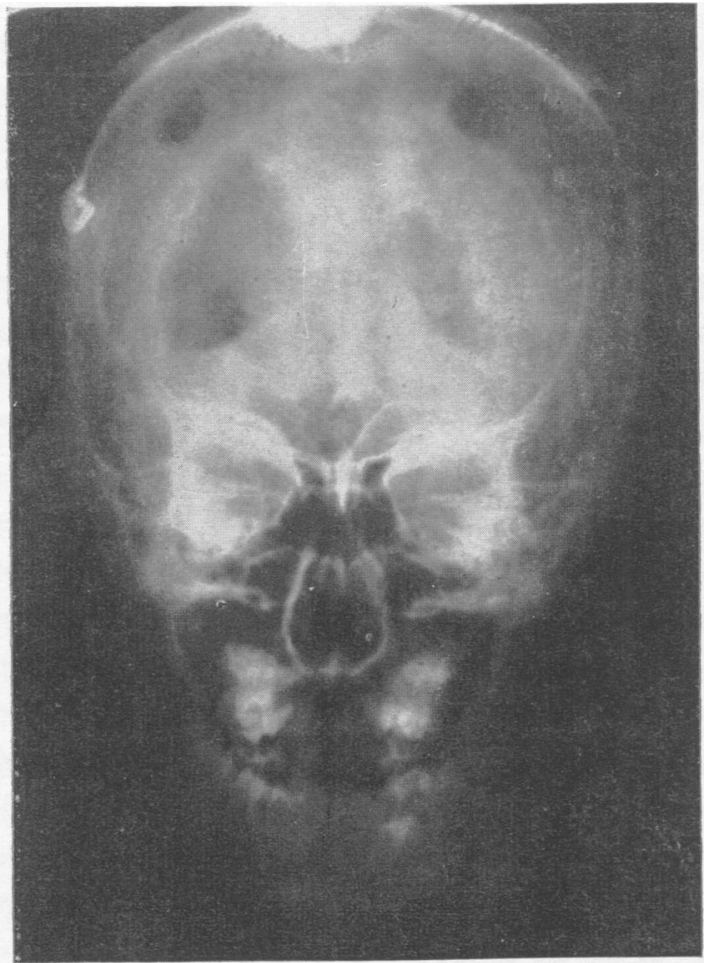

Fig. 27 (Case 7. H.B.).-Ventriculogram.

concerning these convulsions. The child had not attempted to sit up, crawl, or talk.

On examination, the fortanelles were found to be closed; there was a suggestion of a left visual field defect to menace. The left limbs were shorter than the right and the left arm tended to be spastic, the limb held in flexion with the fingers closed. Power and movement in the left leg was noted to be deficient, but relatively better than in the left arm. The left plantar response was strongly extensor, but on the right side the response was doubtful. The child made no attempt to sit up or crawl.

In September, 1948, the child was admitted, and during the preoperative period in hospital, which lasted some six weeks, he lay in bed screaming most of the day, and throwing the right arm and leg around in a repetitive circular type of movement, which would go on for hours on end. There were feeble attempts at moving the left arm. Ventriculography was carried out and revealed a considerable dilatation of the right ventricle (Fig. 23).

Operation (October 22, $1948 . \quad$ Hemispherectomy).Considerable malformation, in the nature of a porencephaly with an adjacent paraventricular cyst, was found in the right hemisphere. The thinned-out brain substance will be seen underlying the EEG markers Nos. 7, 8, and 9 in the operation photograph (Fig. 24). Fig. 25 shows the EEG tracings recorded from the marker positions indicated in the previous figure. The flat records from the positions 7,8 , and 9 overlying the cystic malformations are interesting, but do not need explanation.

Routine hemispherectomy was carried out. The child's condition gave no cause for alarm during operation. On returning to the ward he became very restless, and then suddenly collapsed and died.

Case 7 (Serial No. 3615. H.B., Male).-This child, aged 9 years 5 months, was admitted to the neurosurgical department of the Johannesburg Hospital on February 7, 1949. His mother was distressed because the right arm and leg were weak and spastic, and because he was "very backward mentally". He was the survivor of twins delivered by Caesarian section. He had never used the right limbs as well as the left, and as he grew older the shortening and clumsiness of the right arm and leg became more obvious. No fits or minor episodes occurred at any time, but during the past three to four years he had been having increasingly frequent bouts of violent tempers. These would last from a few minutes up to half an hour, and during these bouts he would salivate profusely, scream, kick, and attack any one near him. Mentally he was very retarded, and in this respect he was becoming progressively worse.

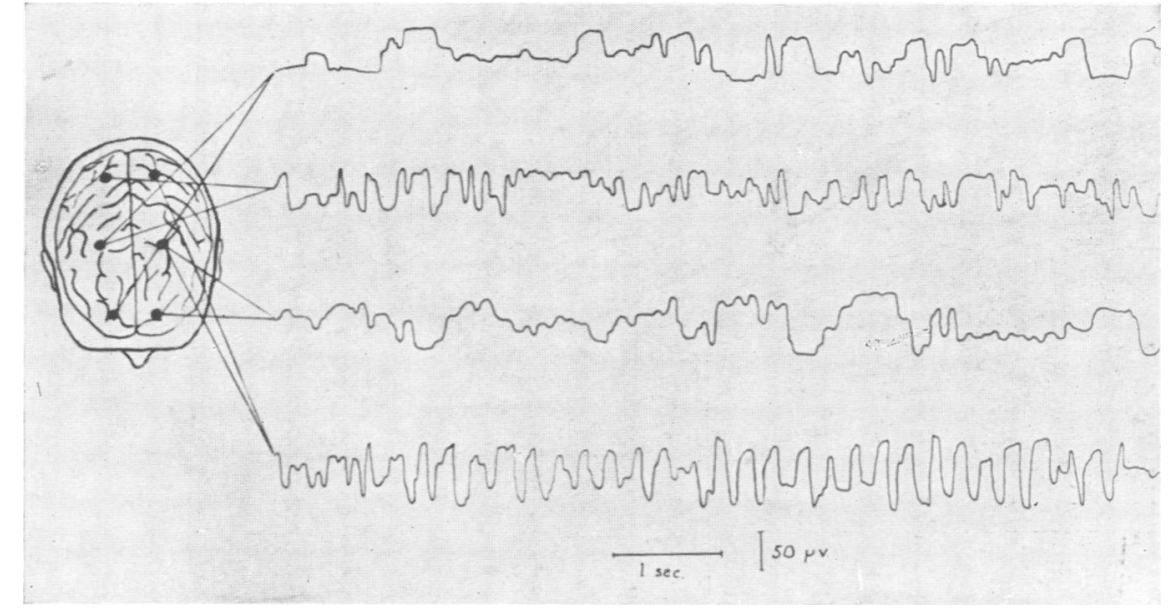

FIG. 28 (Case 7. H.B.).-Pre-operative EEG tracings. 


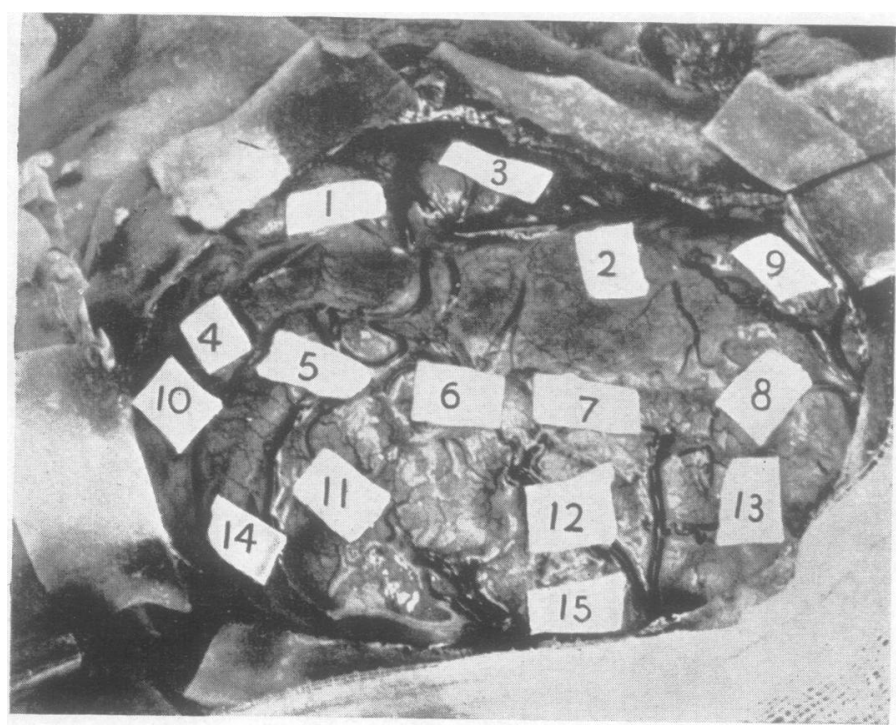

Fig. 29 (Case 7. H.B.).-Cortex exposed at operation.

FIG. 29

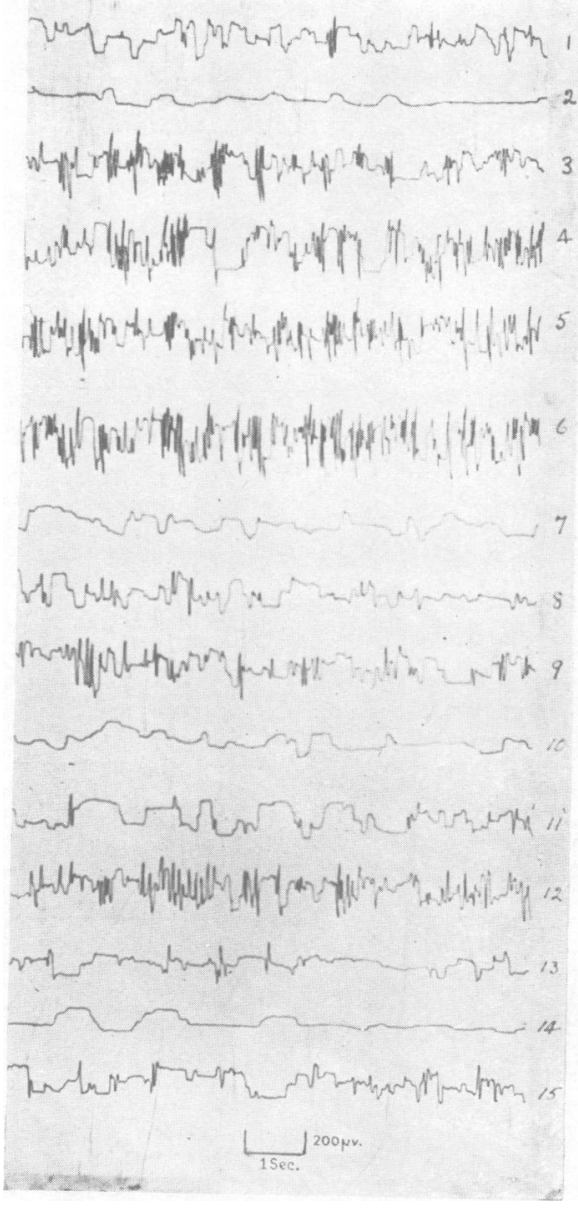

FIG. 30 (Case 7. H. B.).Electrocorticograms.

FIG. 30 
Two years previously he could do simple additions, but had lost this facility, and his ability to read had also deteriorated. He had become restless, and his span of attention was poor. Of particular interest here was the fact that two and a half years before admission to hospital he was considered a fairly bright child, but now he appeared to have forgotten all that he had previously learnt. Apart from a limited vocabulary there was no disturbance of language function, and he was left-handed.

On examination, the cranial nerves showed no abnormalities worth noting, and the visual fields were full to confrontation tests. He had a right spastic hemiplegia with contracture deformities, and shortening of the affected limb. These points are well brought out in the accompanying photographs (Fig. 26).

On the sensory side pin prick, cotton wool, and vibration were normally appreciated throughout. His postural sensibility was somewhat diminished in the fingers of the right hand. Tendon jerks were all brisker on the right, the right abdominal reflexes were absent, and the right plantar was of the extensor type.

Ventriculography showed considerable dilatation of the body of the left ventricle, but the left temporal horn did not fill. Some dilatation of the right ventricle was also noted (Fig. 27).

EEG records were taken and are shown in Fig. 28.

Operation (March 14, 1949. Hemispherectomy).At oparation the left hemisphere was exposed, and a large circular surfacing "watery cyst", $4 \mathrm{~cm}$. in diameter, was encountered in the lower Rolandic line, and extending into the temporal lobe and down to the wall of the ventricle. The cyst can be clearly seen in the photograph (Fig. 29) underlying the marker No. 2.

Electrocorticograms were then recorded and are reproduced in Fig. 30.

Thyratron stimulation of the cortex was then carried out, but no responses were obtained. The reason for this became clear later in the operation when the region of the internal capsule was found to be replaced by a multilocular cystic formation, surrounded by leathery gliosis. I would like to draw attention to the fact that this patient had never had convulsive episodes, manifest in the motor somatic sphere, but that he had had numerous emotional outbursts which might be regarded as epileptic equivalents.

Case Comment.-During the past nine months this boy has made satisfactory progress, apart from the fact that the function of the right arm and leg is of the same order as before the operation. There have been no further emotional outbursts. $\mathrm{He}$ has become a quiet and thoughtful boy and applies himself diligently to tasks and amusements.

Case 8 (Serial No. 3859. R.P., Female).-This child, aged 2 years 9 months, was admitted to the Johannesburg Hospital in February, 1949. She had been perfectly healthy until the age of 10 months, was crawling well, and could say " Mama ", "Dada". At this time she was suddenly taken ill with convulsions and acute otitis media. Penicillin was given and a paracentesis performed. About 36 hours after this the right arm and leg were found to be paralysed. After some months power on the right side gradually returned, but the limbs remained very weak and spastic. Some months after the illness she started having convulsive episodes, starting on the right side, and these increased in frequency, and, at the time of admission, she was having several episodes each day despite sedation. She had been seen by the late Dr. George Riddoch, who diagnosed a venous thrombosis and offered a very poor prognosis.

On examination, she was found to be extremely restless, and responded to attempts at examination by violent outbursts of screaming, kicking, and fighting. Her speech had shown but little development during the two years since her illness, and although the parents had worked very hard at this aspect of her education she could only use some five or six simple isolated words. She was starting to walk, but clumsily, and with assistance. Detailed examination of the cranial nerves was impossible, but she did appear to have a field defect on the right side, and there was some right lower facial weakness. The right arm and leg were less well developed than on the left ; they were spastic and the movements of the right side were extremely clumsy. Ventriculozraphy revealed a gross generalized dilatation of the left lateral ventricle (Fig. 31).

Operation (March 18, 1949. Hemisph rectomy).The left hemisphere was exposed. No gross focal pathology was seen, but the whole hemisphere appzared somewhat shrunken and the gyri small. Needling of the hemisphere revealed a general toughness of the whole structures (Fig. 32).

Electrocorticograms were recorded and the tracing is reproduced in Fig. 33.

The cortex was stimulated with a view to mapping out the motor cortex, but no responses were obtained.

The post-operative course was uneventful and within a few days the movements of the right arm and leg had returned to the pre-operative level. Of particular interest was the fact that when I visited her the day after oparation and asked her where her mummy was, she responded by saying, "Mummy outside". From that time on she started learning new words rapidly, and also started putting them together to construct sentences.

Case Comment.-The child was discharged from hospital a month after operation, and I have not seen her since, but a letter from hei mother seven months after operation gives the following information :

"First let me say that her mental improvement is remarkable. She has a normal vocabulary for a child of her age, if indeed it does not exceed normal, and her pronunciation is perfect. She has an extremely sharp parception of all that goes on around her. She runs about a lot, the movement of her leg having greatly improved. She takes much more notice of her right hand, and it is gaining strength and usefulness from the many movements she attempts throughout the day."

Case 9 (Serial No. 4158, D.S., Female).-This girl, aged 15 years, was admitted to hospital on May 22, 


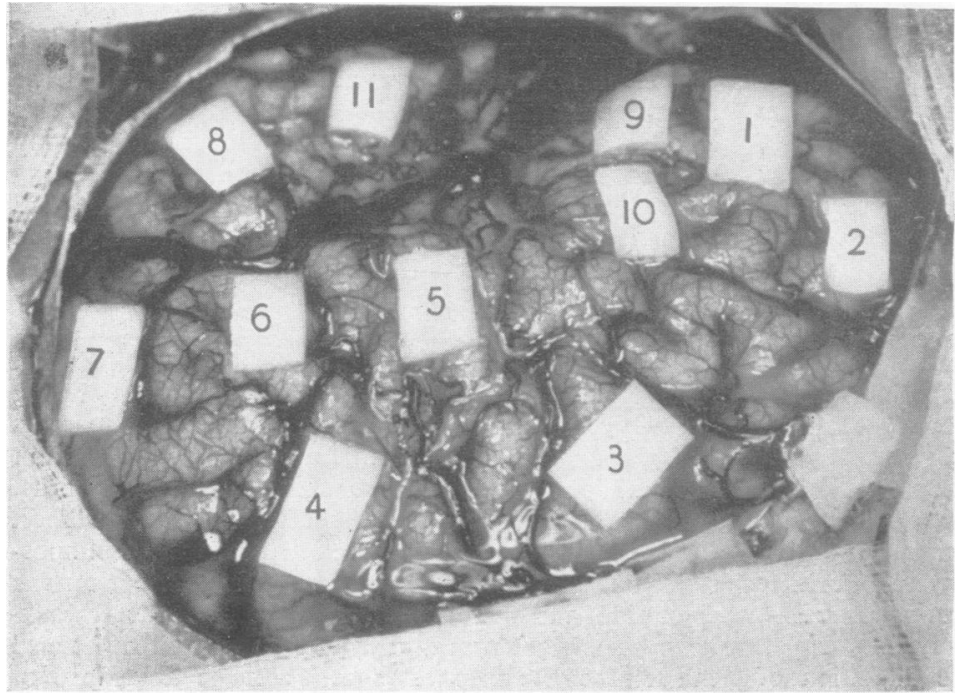

Fig. 32 (Case 8. R.P.).-

Fig. 32

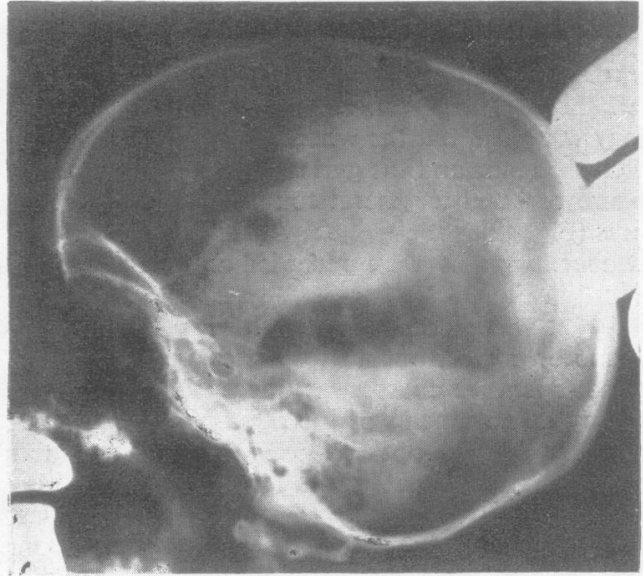

Fig 31

Fig. 31 (Case 8. R.P.).-Ventriculogram.

Fig. 33 (Case 8. R.P.).-Electrocorticograms.

Fig. 33
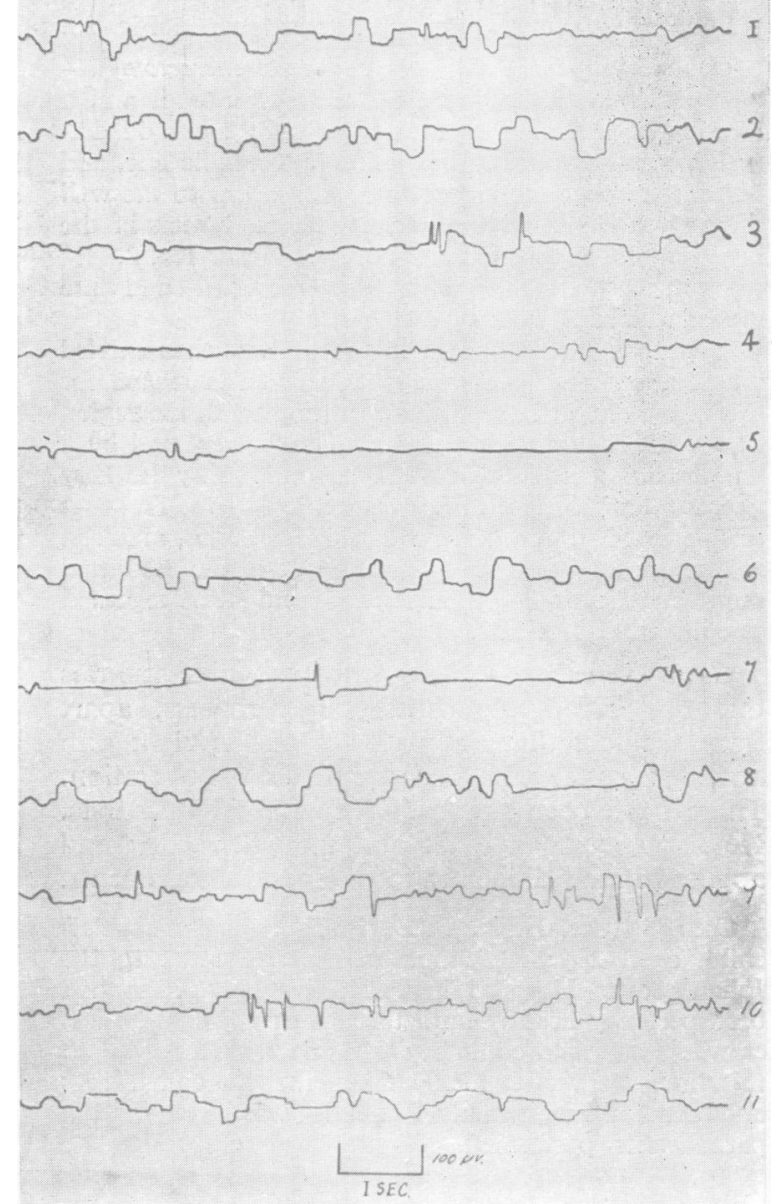
1949. There was a story of difficult birth, but mental and physical development were regarded as being entirely normal up to the age of $4 \frac{1}{2}$ years. At $4 !$ years of age she became very ill, and was admitted to the Childrens' Hospital with a diagnosis of encephalitis. She remained in hospital for six months, and during this time weakness and clumsiness of the right hand were first noticed. Soon after leaving hospital she started having "blank spells" which were diagnosed as petit mal by a senior pxediatric consultant. The nature of the episodes changed during the next year or two. They were still of a relatively minor character, but the head and eyes would turn to the left and both arms would be drawn up and out to the right. During the 18 months before she was admitted under my care she developed in addition to these attacks, generalized convulsive episodes. In all she was having three to seven major and minor episodes each day, despite determined sedative measures. This child had a quiet, placid temperament, and was not prone to emotional upsets. Her school record had been quite good and above average for her age. Of late she had become less interested in things and people, but not more so than one would expect in a child who was having numerous fits, combined with a generous presentation of sedative drugs.

On examination she was seen to be a well-built girl tending to adiposity. The menarche was at 13 years, and her periods were regular. She was a good witness and showed good insight. With regard to the cranial nerves she was found to have generalized constriction for all isoptres in the right homonomous field, and a very slight right lower facial weakness for emotional movements.

The right arm was less well developed than the left and movements, especially distally, were weak and spastic, while purposive movements showed an athetoid clumsiness. There was little fault to be found with the right lower limb except that the tendon jerks were comparatively slightly increased and the right plantar response was regarded as equivocal.

The examination of sensory functions revealed a normal appreciation and localization of pin prick and light touch, but slight loss of all the cortical sensory modalities. Electroencephalography revealed a pərsistent slow wave focus from the left frontal region with suggestion of wave and spike patterns (Fig. 34).

Air encephalography showed the left ventricle to be dilated, but mainly in its posterior half and temporal horn.

Operation (June 15, 1949. Hemispherectomy).-The cortex was exposed in the usual manner, and in general appearance seemed quite normal (Fig. 35).

Electrocorticograms were recorded and are shown in Fig. 36.

In view of these, and because of the ventricular distortion, hemispherectomy was carried out. Three days later, because of haemorrhage into the cavity, the flap had to be re-elevated and the clot dealt with. Thereafter her post-operative course was uneventful, except that movements of the right arm and leg were slow in returning. This raises what I consider to be an important point regarding the function of the caudate nucleus, to which reference will be made later.

Case Comment.-It is now seven months since this patient was operated on. She is bright and cheerful and mentally alert, and looking forward to returning to school in a few weeks' time. Movements of the right side are improving satisfactorily but are not yet up to the pre-operation level. This applies particularly to the right lower limb. There have not been any fits or suggestive episodes since operation.

Case 10 (Serial No. 2453, P.T., Male).-This boy, aged 14 years, was referred to the Neurosurgical Department on April 11, 1948. He is an only child. Birth was difficult and instruments were used. When he was 6 months of age the parents first noticed that the left arm and leg were weak. Mentally his development was satisfactory, but walking was delayed until he was over 2 years of age. The left arm seemed to become progressively more clumsy, and lagged behind in general development and growth. At about $2 \frac{1}{2}$ years of age he started having "funny turns", in which he went very pale and giddy. At 8 years of age he was operated on by an orthopaedic surgeon for the contracture deformity of the left foot. By this time he was having frequent episodes in which he complained of " funny little sho:ks" in the left hand which were associated with a drawing up of the left hand and arm, but without 1 iss of consciousness. The left arm became gradually more spastic, deformed and useless. More recently he had become aggressive and bad tempered, and terrified of impending attacks. Sedative medication failed to control the episodes.

On examination the cranial nerves showed no deviations worth recording. The left arm and leg were not so well developed as the right, being both shorter and thinner. The left arm was flexed and adducted, the grip on the left was poor, and he was unable to extend the wrist or fingers. The tendon jerks on the left side were all increased by comparison with the right, and the plantar response was of the extensor type. In the sensory sphere he showed defective postural sensibility, and impaired two point discrimination. Pin prick and cotton wool were normally appreciated, but localization of these modalities was not accurate in the left upper limb. Ventriculography was carried out. The brain felt leathery to the advancing brain needle, and t'e air pictures showed slight dilatation in the region of the vestibule of the right ventricle. Electroencephalography revealed a generalized dysrhythmia with a focus of high amplitude three to four par second discharge from the right temporo-parietal zone.

First Operation (May 14, 1948).-A right lateral osteoplastic flap was turned and revealed a zone of microgyral formation occu,ying a considerable part of the right parietal lobe and extending forwards to the Rolandic fissure. The motor cortex was mapped out by stimulation. Block excision to a depth of $3 \mathrm{~cm}$. of the parietal lobe, to include the microgyral formations and extending forward to include the motor arm area, was 


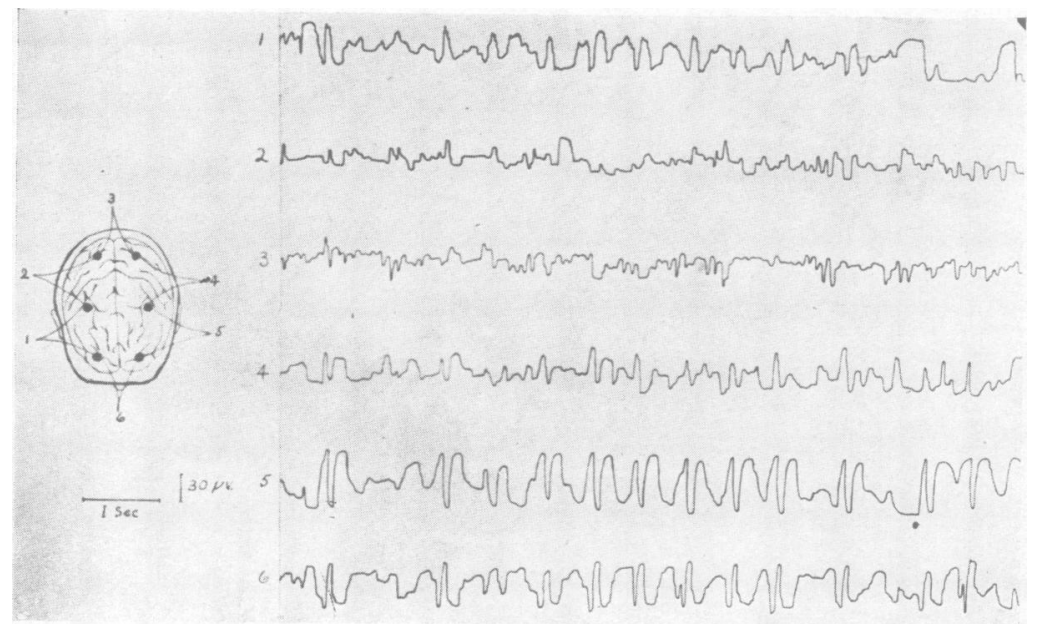

FIG. 34

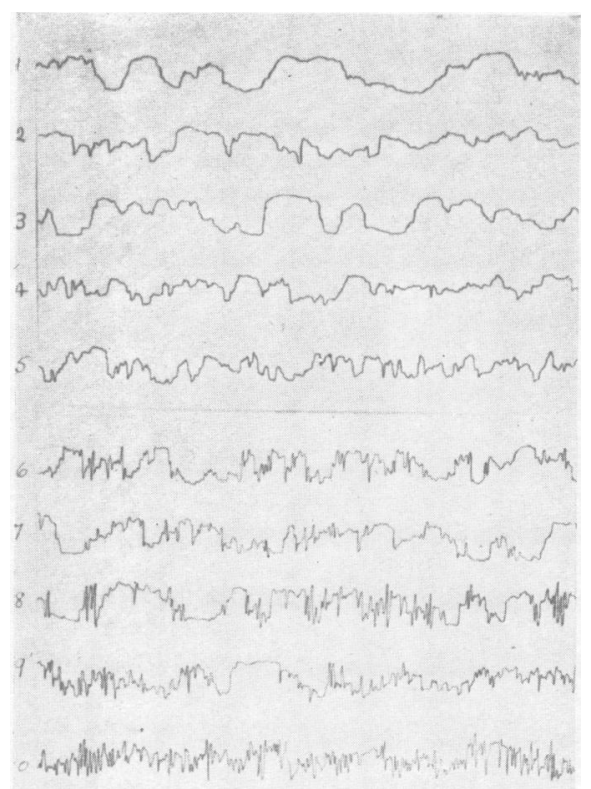

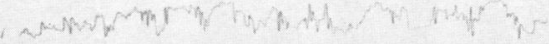

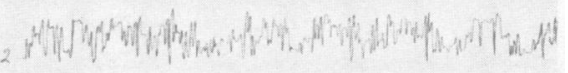

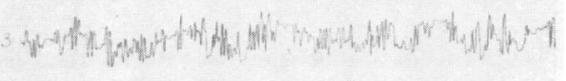

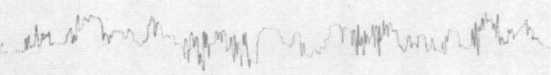

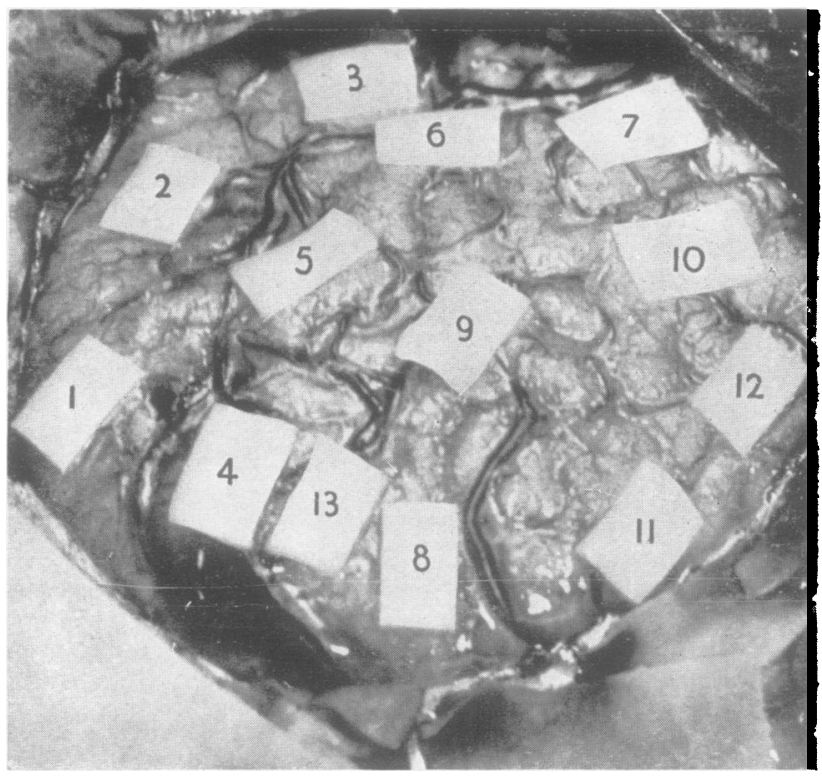

Fig. 35

FIG. 34 (Case 9. D.S.).-Pre-operative EEG tracings.

Fig. 35 (Case 9. D.S.).-Cortex exposed at operation.

FIG. 36 (Case 9. D.S.).-Electrocorticograms.

FIG. 36 
carried out. He was discharged from hospital three weeks later. Movement on the left side showed some improvement on the pre-operative level.

Case Comment.-For three months the boy was perfectly well and then the attacks started again, but were somewhat modified. There was no sensory component, but the head and eyes would be pulled over to the left and he would then have clonic twitching in the left arm. The left leg was not involved. These attacks were of particular interest to us because the motor arm area had been removed at operation. He was re-admitted in October, 1949, because of the attacks being as frequent as before operation, and because they did not respond to aggressive sedative measures. In view of my previous experience with limited cortical excisions I decided to remove the entire hemisphere.

Second Operation (November 1, 1949 : Hemispherectomy).-His post-operative course was uneventful and he was up and about three weeks after operation, with movements quite up to the pre-operative level. After a further week he was allowed home. His progress will be carefully followed.

Case 11 (Serial No. 120, E.G., Female).-This child, aged 13, was first seen by me in June, 1943, when she was 7 years of age. She exhibited a right hemiplegia of the infantile type, was having fits starting in the right arm, and also numerous petit mal episodes. Mentally she was very retarded and was difficult to handle. She was put in an institution where she remained for the next six years, until she was admitted to the Neurosurgical Department. Her mental age was assessed at 5 years. Air encephalography revealed some dilatation of the left ventricle (Fig. 37).

EEG studies were carried out and are shown in Fig. 38.

Operation (December 14, 1949 : Hemispherectomy).The cortex was exposed in the usual manner. There was no evidence of microgyral formation or gross pathology, apart from the fact that the sub-arachnoid space was very wide, and contained large, looping arteries, which looked like small pulsating worms, over the entire extent of the cortex. No motor responses were obtained when the cortex was stimulated. Later during the operation the region of the internal capsule was found to be the site of a firm leathery gliosis. It is now only a few weeks since operation and too early to make any comment regarding her progress.

Case 12 (Serial No. 4557, M.B., Female).-The child, aged 7 months, was admitted on December 22, 1949. On November 21, 1949, she had fallen from a bed onto the floor. One hour later she became unconscious and remained so for two days. It was then noticed that the right arm and leg were paralysed. On November 29 the surgeon, to whom the case had been referred, trephined the left side of the skull and evacuated a large extradural clot through an opening 1 in. in diameter. The paralysis improved remarkably for a couple of weeks. The right arm and leg then became weak again, and the region of the trephine opening bulged, and finally broke down discharging a serosanguinous fluid in a pulsatile manner. I decided to turn a flap and deal with any remaining extradural collection, and at the same time expose and inspect the cortex.

Operation (December 28, 1949 : Hemispherectomy).The anaesthetic used was $7 \mathrm{c} . \mathrm{cm}$. syrup of chloral, and local $1 \%$ novocaine.

A left lateral flap was turned and a large organizing tarry extradural blood clot was found and dealt with. This clot was found to be overlying the entire hemisphere posterior to the Rolandic line. On opening the dura the posterior half of the hemisphere behind Rolando was found to be pale, oedematous, and with convolutional widening and a generally necrotic appearance. Needling revealed a multilocular cystic formation, the cystic fluid baing of a milky appearance. The cysts were not communicating with the ventricle. I started by amputating the posterior half of the hemisphere, but on encountering a gross generalized dilatation of the entire left ventricle, I proceeded to carry out a complete hemispherectomy as defined in this report.

Case Comment.-This baby is making excellent post-operative progress. Movements on the right side were present immediately after the hemisphere was removed, but by the next morning there was very little movement and the right arm and leg were rather spastic. On the fifth post-operative day power in the arm and leg started to return, and now two weeks later are regarded as good as on the opposite side, although the patient definitely favours the left side. She is an extremely bright, observant, and happy child. Her subsequent progress will be followed with the greatest interest.

\section{Discussion}

In the foregoing protocols I have tried to confine myself to the more positive aspects of each case. No mention is made of C.S.F. pressures and analysis, Wassermann reactions, or blood counts, because no significant changes in these were noted. The number of cases reported here is too few, and in most cases the interval since operation too short, to be dogmatic about results, but one can at least say that these are promising.

Epilepsy, either focal or generalized, was present in 10 out of 12 cases, and in all these the epileptic manifestations have ceased after operation without sedative medication. Disorders of behaviour and personality are a marked feature of this group of cases, and the profound betterment in respect of mentality in all cases exceeds our best expectations. It should be pointed out that this improvement in the mental sphere, presupposes, and is dependent upon, the integrity of the remaining hemisphere and its ability to function normally once it has been 

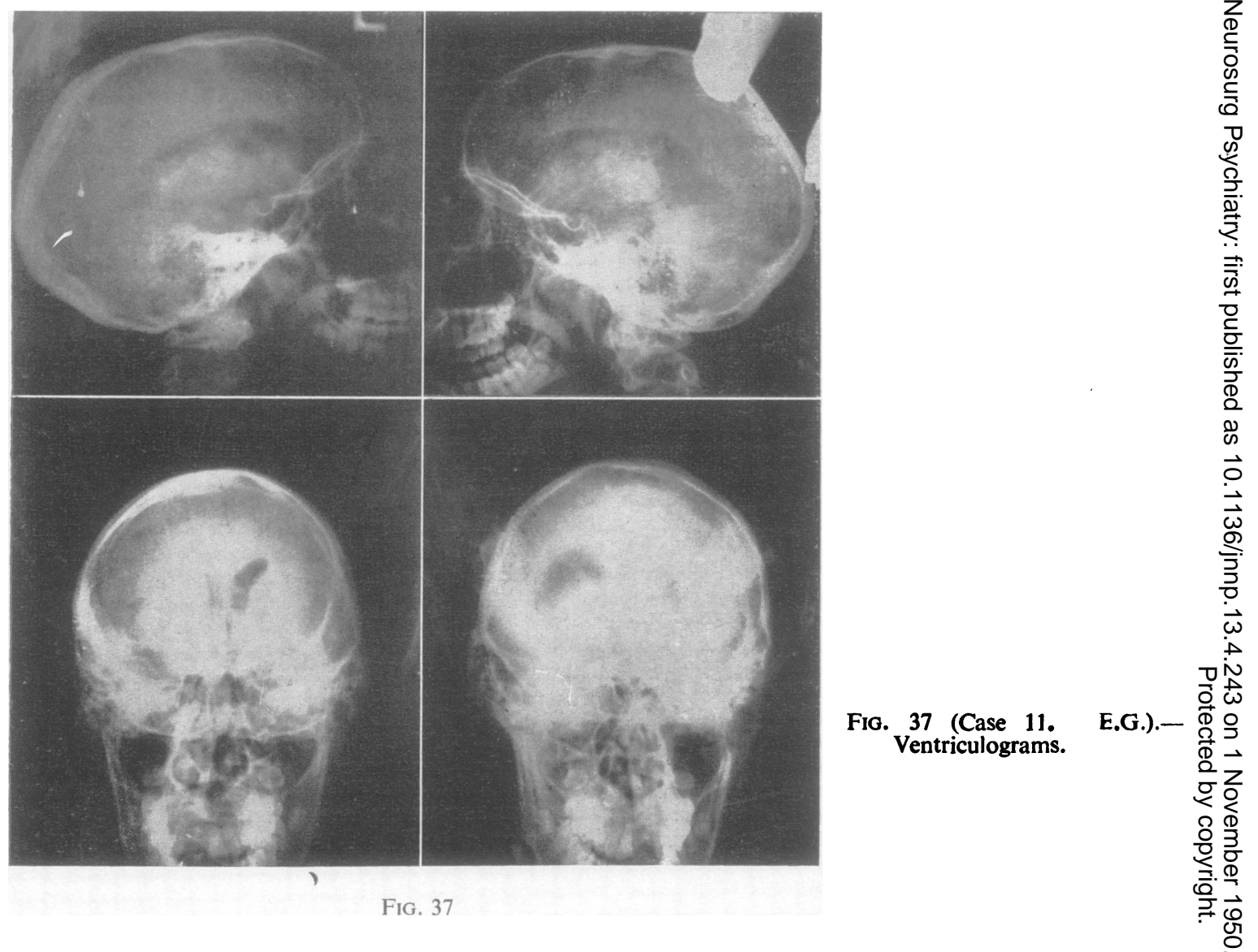

FIG. 37

FIG. 38 (Case 11. E.G.). EEG.

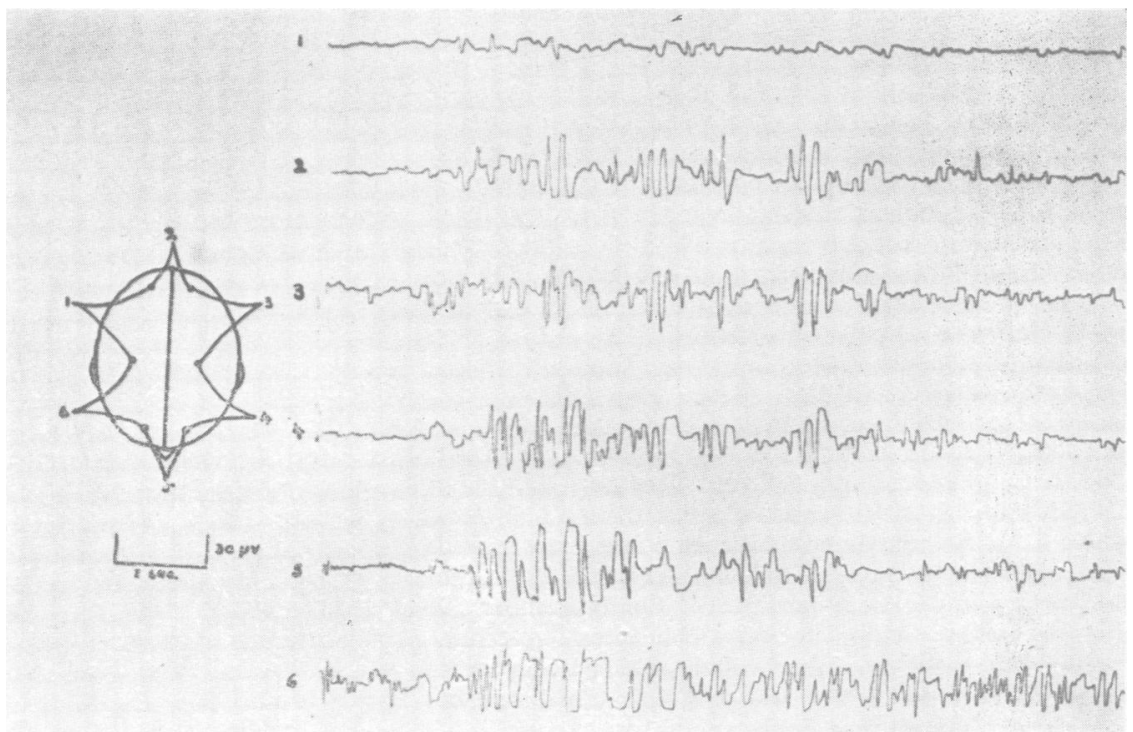

Fig. 38 
released from abnormal influences from the pathological side.

Although return of function and power to the pre-operative level was predicted and expected in these cases, improved tone and function beyond this level has been a happy by-product of the operation, and is perhaps a little difficult to explain. If the caudate nucleus is removed with the hemisphere there is little or no return of voluntary and useful motor activity. This point is well brought out by a study of the earlier cases of hemispherectomy as carried out by Dandy, Gardner, and others in cases of brain tumour. What of the lentiform complex, putamen, and globus pallidus? The results indicate that this should be included in the removal, a hypothesis supported by a careful consideration of anatomical pathways, and the frequency with which we find associated pathology in the region of the lentiform complex in these cases of infantile hemiplegia. It would appear reasonable to assume that the ipsilateral hemisphere has some control over the volitional act, but that this control is via the caudate nucleus of the contralateral side.

On the sensory side we have found that localization of pin prick returns after a few months with only a minimal defect of accuracy. Joint sense has also returned with the lapse of time in at least two cases. It is accurate at the larger joints, shoulder, elbow, hip and knee, and in one case accurate at the wrist, and again in one case accurate for gross movements of the fingers. Two point discrimination with an increased threshold-about three times the normal-has been present in two of the cases examined.

With regard to the language function, I suppose one might argue that hemisphere dominance had adjusted itself before removal of the affected hemi- sphere, and that it was the minor hemisphere which was removed in all cases. Such an argument would be comfortable, and in conformity with accepted principles. Nevertheless, careful study of some of the cases reported above, particularly Case No. 8, makes one wonder whether such an easy acceptance of the position is not causing $u$; to overlook some of the most interesting and important facts which may emerge from this work.

It is, I think, worth noting that apart from the loss of cortical sensory modalities referred to above, there has been an entire absence of those changes, such as spatial disorientation and disturbance of body image, which we have come to associate with disturbances of the parietal cortex.

\section{Summary}

Hemispherectomy has been carried out in $12^{*}$ cases of infantile hemiplegia. There has been one death in the series.

Epilepsy and mental changes, either singly or in combination, are regarded as indications for the operation.

Post-operative return of motor power with lessening of the spasticity and clumsiness has been a feature in these cases.

Marked improvement in personality, behaviour, and mentality has been noted in all cases.

I should like to take this opportunity of thanking Mr. K. Lewer Allen, my first assistant, Dr. I. Siff, my anaesthetist, and all the other members of the medical and nursing staff for their unfailing enthusiasm and tireless attention to the patients whose welfare forms the theme of this communication.

* Since going to press eight more cases have been operated upon and are making satisfactory progress. 